\title{
Revisão dos gêneros Prionolopha e Securigera (Orthoptera, Romaleidae, Romaleinae)
}

\author{
Sidney Moraes de Vasconcellos
}

Departamento de Entomologia, Museu Nacional, Universidade Federal do Rio de Janeiro, Quinta da Boa Vista, São Cristóvão, 20940040 Rio de Janeiro, RJ, Brasil. (smvasconcellos@mn.ufrj.br)

\begin{abstract}
Revision of the genera Prionolopha and Securigera (Orthoptera, Romaleidae, Romaleinae). A revision of the genera Prionolopha Stål, 1873 and Securigera Bolívar, 1909 based on the examination of the external morphology of male and female and the spermathecae and phallic complex is given. Prionolopha daguerrei Liebermann, 1935 and P. evoneoi Piza, 1981 are considered synonyms of $P$. serrata (Linnaeus, 1758). Alcamenes cristatus Bruner, 1906 is transfered to genus Securigera Bolívar, 1909. Illustrations of each species and a map of the geographical distribution are also included.
\end{abstract}

KEYWORDS. Taxonomy, Romaleidae, morphology, Prionolopha, Securigera.

RESUMO. Realizamos a revisão dos gêneros Prionolopha Stål, 1873 e Securigera Bolívar, 1909, baseada no exame da morfologia externa de machos e fêmeas, espermateca e complexo fálico. Consideramos Prionolopha daguerrei Liebermann, 1935 e P. evoneoi Piza, 1981 sinônimos de P. serrata (Linnaeus, 1758). Transferimos Alcamenes cristatus Bruner, 1906 para o gênero Securigera Bolívar, 1909. Incluímos figuras de cada espécie e o mapa de distribuição geográfica.

PALAVRAS-CHAVE. Taxonomia, Romaleidae, morfologia, Prionolopha, Securigera.

O gênero Prionolopha Stål, 1873 foi estabelecido a partir da revisão das espécies de Orthoptera descritas por Linnaeus, De Geer e Thunberg e proposto para $P$. serrata (Linnaeus, 1758). Securigera Bolívar, 1909, baseado em exemplares procedentes de Sapucay (Paraguai), foi proposto para abrigar S. acutangula Bolívar, 1909. Ambos são gêneros neotropicais cujos registros de ocorrência incluem, para o primeiro, localidades do Panamá à Argentina (Corrientes) e Brasil (Mato Grosso do Sul) e Paraguai para o segundo.

Desde a $10^{\mathrm{a}}$ edição do Systema Naturae, na qual Linnaeus descreveu Gryllus (Bulla) serrata, outros táxons foram estabelecidos contribuindo para uma extensa lista de combinações e sinonímias relacionadas com P. serrata (KIRBY, 1910). No histórico relacionado a Prionolopha, constatamos que as variações morfocromáticas dos exemplares examinados sempre despertaram a atenção dos autores que se ocuparam do gênero, pois em seus comentários sempre referiam-se a essas variações como um dos critérios de distinção entre as espécies descritas. De Geer (1773), por exemplo, comentou que Acrydium serrato-fasciatum e A. serratum, sinônimos de $P$. serrata, dispunham de inúmeras características semelhantes embora fossem facilmente distintas pela presença ou ausência de faixas claras. Thunberg (1815) também evidenciou diferenças morfocromáticas sutis entre Pamphagus lateralis e Pamphagus serratus, também sinônimos de $P$. serrata. A partir de STÅL (1873) outros autores evidenciaram que Prionolopha tratava-se de um gênero com ampla variação morfológica. BRUNER (1900) considerou possível a revelação de novas formas a partir de um estudo mais cuidadoso em função da variação morfológica existente entre exemplares de diferentes procedências. ReHN (1907) teceu breve comentário a respeito da variação de tamanho e cor dos exemplares de Prionolopha coletados em Sapucay (Paraguai). LieBERMAnN (1935), com base na maior altura da crista média do pronoto em uma fêmea de Prionolopha, descreveu P. daguerrei. Esse mesmo autor, em 1946, referiu-se a variação no comprimento, cor e altura da crista média do pronoto em fêmeas de P. serrata considerando necessária maior quantidade de exemplares para esclarecer a existência de outras formas e, em 1958, comentou que, de posse de amplo material do gênero talvez fosse possível estabelecer a coespecificidade entre $P$. serrata e $P$. daguerrei.

Aliado ao citado anteriormente, Giglio-Tos (1900) descreveu Prionolopha brevipennis que, segundo ele, seria semelhante a $P$. serrata, diferindo dessa quanto ao comprimento das tégminas. Bolívar (1909) sugeriu, segundo ele sem o conhecimento da espécie, a transferência de $P$. brevipennis para Securigera em função da ausência de caracteres que justificassem a permanência desta em Prionolopha. Bruner (1911) transferiu $P$. brevipennis para o gênero Alcamenes Stål, 1878 , embora não estivesse seguro de que o exemplar de que dispunha fosse de fato pertencente à espécie descrita por Giglio-Tos (1900). Em 1955, LieBERMANN citou o epíteto Securigera brevipennis possivelmente como sinônimo de $P$. brevipennis, embora não tenha tecido qualquer comentário a respeito. Finalmente, PizA (1981) descreveu P. evoneoi, na qual evidenciou a presença de faixa "lútea" no exemplar examinado. Assim, baseado no exposto até aqui, Prionolopha abrigaria $P$. serrata, $P$. daguerrei e $P$. evoneoi.

No que tange a Securigera, o primeiro elemento a ser considerado é o fato deste incluir indivíduos braquípteros e possivelmente confundidos com formas 
imaturas do outro gênero sob revisão nesse trabalho, podendo ser essa a razão para o pequeno número de registros de Securigera em áreas tão sistematicamente visitadas por acridólogos ao longo de décadas. Outro dado que reitera a dúvida quanto à validade ou não desse gênero é o fato de que Alcamenes cristatus Bruner, 1906 e Securigera acutangula Bolívar, 1909 foram descritas com base em exemplares da mesma procedência tendo assim a mesma localidade-tipo, Sapucay (Paraguai). Tal informação não seria por si só motivo de questionamento não fosse o fato de, ao examinarmos as fotografias dos tipos e compará-las com os exemplares da coleção do Museu Nacional, constatarmos que ambas são muito semelhantes morfologicamente de tal forma que suas descrições aplicam-se tanto aos exemplares de uma quanto aos da outra. Ao comentário feito às duas espécies anteriores, agrega-se de que ambas não dispõem dos caracteres que definem morfologicamente o gênero Alcamenes, que, apesar de não estar incluído na presente revisão, abriga epíteto citado como possível sinônimo de $S$. acutangula.

Com base no citado acima e no histórico de Securigera, este abrigaria S. acutangula Bolívar, 1909.

\section{MATERIAL E MÉTODOS}

Examinamos 301 exemplares de Prionolopha e seis de Securigera, todos integrantes da coleção de acridóideos do Departamento de Entomologia do Museu Nacional. Embora os tipos de Gryllus (Bulla) serrata Linnaeus, 1758, P. brevipennis Giglio-Tos, 1900, $P$. daguerrei Liebermann, 1935, P. evoneoi Piza, 1981, Alcamenes cristatus Bruner, 1906 e S. acutangula Bolívar, 1909 não tenham sido examinados, pudemos comparar exemplares dessas espécies na coleção com as fotos dos respectivos tipos cedidas pelo Prof. C. S. Carbonell. Dois exemplares de $A$. cristatus Bruner, 1906, que integram a coleção e foram comparados com o material-tipo, também foram examinados.

As medidas citadas no texto correspondem àquelas utilizadas por CARBonEll (1995) (A a Q). A essas medidas acrescentamos outras duas e quatro outros parâmetros que consideramos relevantes: $\mathrm{R}$, maior altura do pronoto; $\mathrm{S}$, maior altura do lobo lateral do pronoto; a e a', plano paralelo ao maior eixo corporal e tangente ao fastígio; b e b', plano paralelo ao maior eixo corporal e tangente ao vértice; c e c', plano paralelo ao maior eixo corporal e tangente à margem superior dos olhos e d e d', plano paralelo ao maior eixo corporal e tangente à carena lateral do disco (fig. 1).

Nas redescrições utilizamos terminologia conforme SNODGRASS (1935), SLIFER (1939) e DiRSH (1956).

As siglas das instituições citadas referem-se a: Museu Nacional, Universidade Federal do Rio de Janeiro, Rio de Janeiro, Brasil (MNRJ); Universidade Complutense, Departamento de Biologia Animal, Madri, Espanha (UCME); Linnean Society United Kingdon, Londres, Inglaterra (LSUK).

\section{Prionolopha Stål, 1873}

Prionolopha STÅL, 1873:27, 44; 1878:14; VON WATTENWYL, 1893:133; Giglio-Tos, 1895:812; 1898:41; Bolívar, 1909:352;
Rehn \& Grant, 1959b:110; Silva et al., 1968:205; Uvarov \& Dirsh, 1961:158; AmEdeGnAto, 1974:198.

Espécie-tipo: Gryllus (Bulla) serratus Linnaeus, 1758, por designação original.

Porte médio a grande; asas desenvolvidas, ultrapassando o ápice do abdome. Machos com comprimento entre 39 e 53 mm e fêmeas entre 67 e $80 \mathrm{~mm}$.

Fastígio do vértice projetado anteriormente, mais largo que longo, subtriangular, com margem anterior curva (figs. 3,18 ). Pronoto estreito, com carenas laterais crenuladas, curvas e divergentes no sentido ânteroposterior, com maior distância na metazona. Disco com margens posteriores retas, crenuladas até o meio, convergentes, com ângulo caudal ultrapassando a inserção do fêmur posterior. Em vista lateral (figs. 2, 19), vértice convexo, fastígio elevado, com margem anterior no mesmo plano do vértice. Olhos pequenos e oblíquos. Pronoto com carena média elevada, reta na prozona ou curva em toda a extensão, serrilhada em todo o comprimento, cortada ou não pelos sulcos anterior, médio e principal. Sulcos subparalelos, com distâncias subiguais. Carena lateral sub-reta, disposta abaixo ou no plano tangente à margem superior do olho. Margem externa do lobo lateral oblíqua, elevada anteriormente e curva. Tórax, em vista ventral, como nas figuras 8 e 24 . Tégminas longas ultrapassando o ápice do fêmur posterior (figs. 27, 28).

Fêmur posterior (figs. 5, 26) com carenas superior e inferior, serrilhadas em toda a extensão.

\section{Prionolopha serrata (Linnaeus, 1758) (Figs. 2-28, 56)}

Gryllus (Bulla) serratus LinNAEus, 1758:427; 1764:121 (lista); FABRICIUS, 1781:363 (lista); ScUDDER, 1868:38 (lista); 1901:130 (lista); KIRBY, 1910:358 (syn.).

Gryllus serratus; FABRICIUS, 1775:288 (lista); KIRBY, 1910:359 (syn.).

Pamphagus serratus; Thunberg, 1815:260 (syn.); Kirby, 1910:359 (syn.).

Tropinotus serratus; Serville, 1831:273 (syn.); 1839:618 (syn.); ERICHSON, 1848:582 (lista); SCUDDER, 1868:83 (lista); WALKER, 1870:529 (cat.); Kirby, 1910:359 (syn.)

Acrydium serratum; De GeER, 1773:489 (syn.); OlIVIER, 1791:216 (lista); Scudder, 1868:7 (lista); KIRBY, 1910:359 (syn.).

Acrydium serrato-fasciatum De GeEr, 1773:495 (syn.); Serville, 1831:273 (syn.); STÅL, 1873:44 (syn.); KIRBY, 1910:359 (syn.).

Xiphocera serrata; BuRMEISTER, 1838:614 (syn.); KirBy, 1910:359 (syn.).

Prionolopha serrata; STÅL, 1873:44 (syn.); PiCTET \& SAUSSURE, 1887:335 (syn.); Giglio-Tos, 1894:16 (dist.); 1895:812 (dist.); 1897:29 (dist.); 1898:52 (dist.); 1900:3 (dist.); Bruner, 1900:55 (dist.); 1906a:150 (dist.); 1906b:644 (dist.); 1907:224 (dist.); 1910:469 (dist.); 1911:43 (dist.); 1913a:181 (dist.); 1913b:461 (dist.); 1919:38 (dist.); ReHN, 1907:169 (dist.); 1909:117 (dist.); 1913:330 (dist.); 1916:283 (dist.); Kirby, 1910:358 (syn.); CAMPos, 1923:21 (dist.); LiebermanN, 1928:147 (dist.); 1935:34 (dist.); 1939:170 (dist.); 1946b:452 (dist.); 1951:46 (dist.); 1955:335 (dist.); 1958:6 (dist.); 1963:64 (dist.); Hebard, 1931:272 (dist.); Roberts, 1941:239 (lista); Liebermann \& Pirán, 1941:10 (dist.); HePPer, 1945:289 (dist.); Liebermann \& Ruffinelli, 1946:10 (dist.); Dirsh, 1956:275 (morf.); REHN \& GRANT, 1959a:249 (morf.); DinTHER, 1960:18 (dist.); HaYWARD, 1960:78 (dist.); Mason, 1969:299 (morf.); Descamps \& Amedegnato, 1970:863 (dist.); Gangwere \& Ronderos, 1975:178 (ecol.); Descamps, 1976:309 (ecol.); 1979:313 (dist.); PASSERIN, 1981:35, 43, 47, 48, 89 (lista); 

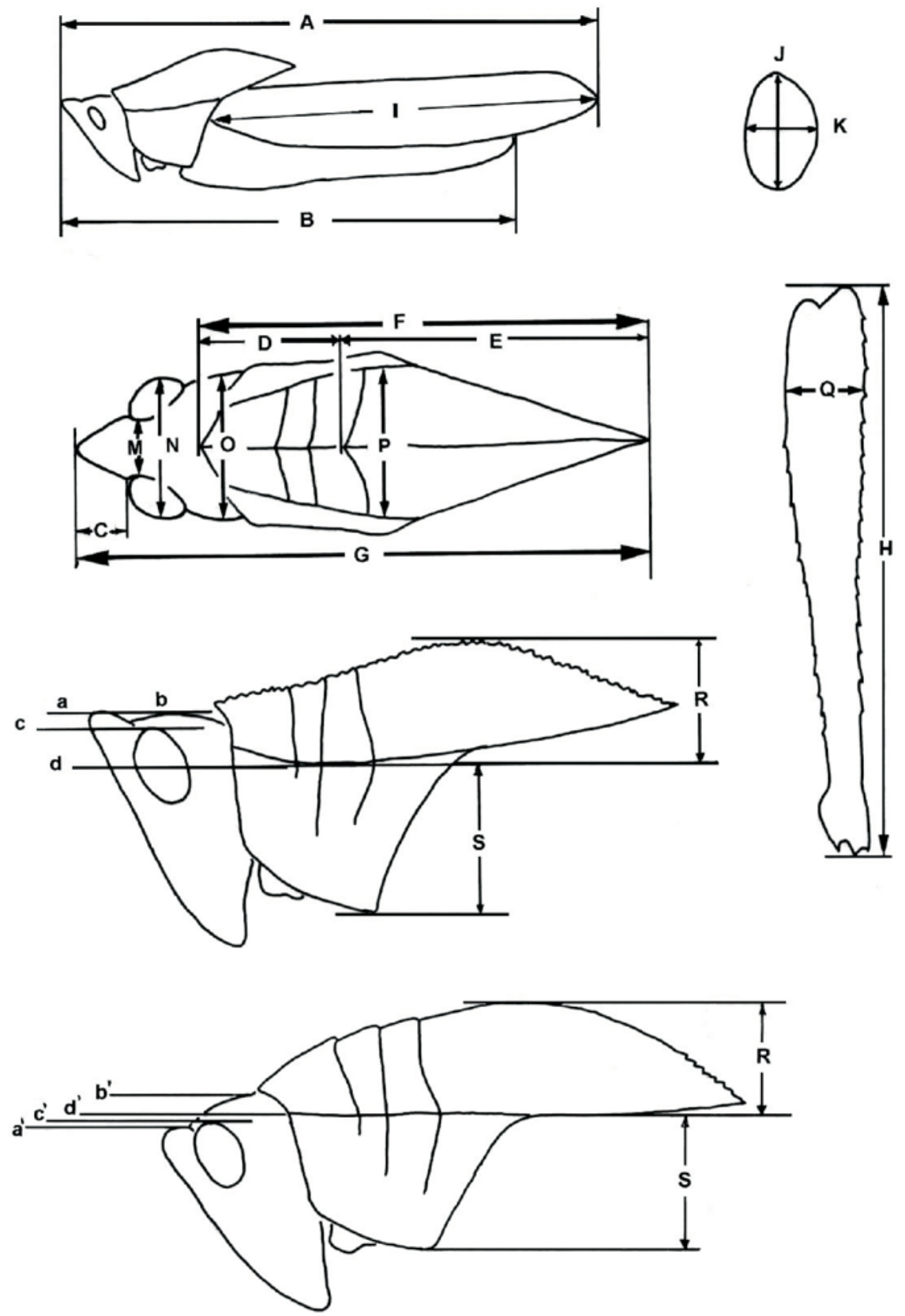

Fig. 1. Desenho esquemático das medidas relacionadas no texto, modificado de Carbonell (1995).

C.O.P.R., 1982:113 (econ.); Mesa et al., 1983:516 (cariol.); Marshall, 1983:379, 392 (cat.); Carbonell, 1986:371 (cit.); Monné, 1990:106,108,117 (lista).

Acrydium dentatum Olivier, 1791:217 (syn.); Serville, 1831:273 (syn.); Kirby, 1910:359 (syn.).

Gryllus locusta cymbiformis STOLL, 1813:12 (syn.); РicteT \& Saussure, 1887:335 (syn.); Kirby, 1910:359 (syn.).

Pamphagus cymbiformis; Blanchard, 1840:38 (syn.); Kirby, 1910:359 (syn.).

Gryllus locusta scutatus Stoll, 1813:39 (syn.); KIRBY, 1910:359 (syn.).

Pamphagus lateralis Thunberg, 1815:260 (syn.); StÅL, 1873:44 (syn.); Scudder, 1868:60 (syn.); 1901:236 (syn.); Kirby, 1910:359 (syn.).

Xiphocera elegans WALKer, 1870:525 (syn.); KIRBY, 1910:359 (syn.).

Prionolopha daguerrei LieBERMAnN, 1935:35 (desc.); 1939:170 (lista); 1946a:236 (lista); 1957:18 (lista); 1958:7 (dist.). Syn. nov.

Prionolopha evoneoi PIZA, 1981:81 (desc.). Syn. nov.

Macho. Cabeça, em vista dorsal (fig. 3), com fastígio sem crista arqueada; vértice com crista média estendendose da margem anterior dos olhos à margem anterior do pronoto; cristas transversais obsoletas e irregulares; olhos projetados externamente com espaço interocular igual ao comprimento do fastígio, elípticos, com maior diâmetro subigual à distância da margem inferior à sutura geno-mandibular; largura da cabeça na altura dos olhos maior que na altura das genas. Em vista lateral (fig. 2), costa frontal sub-reta. Distância entre a costa frontal e a crista pré-ocular maior que a existente entre esta e o sulco 


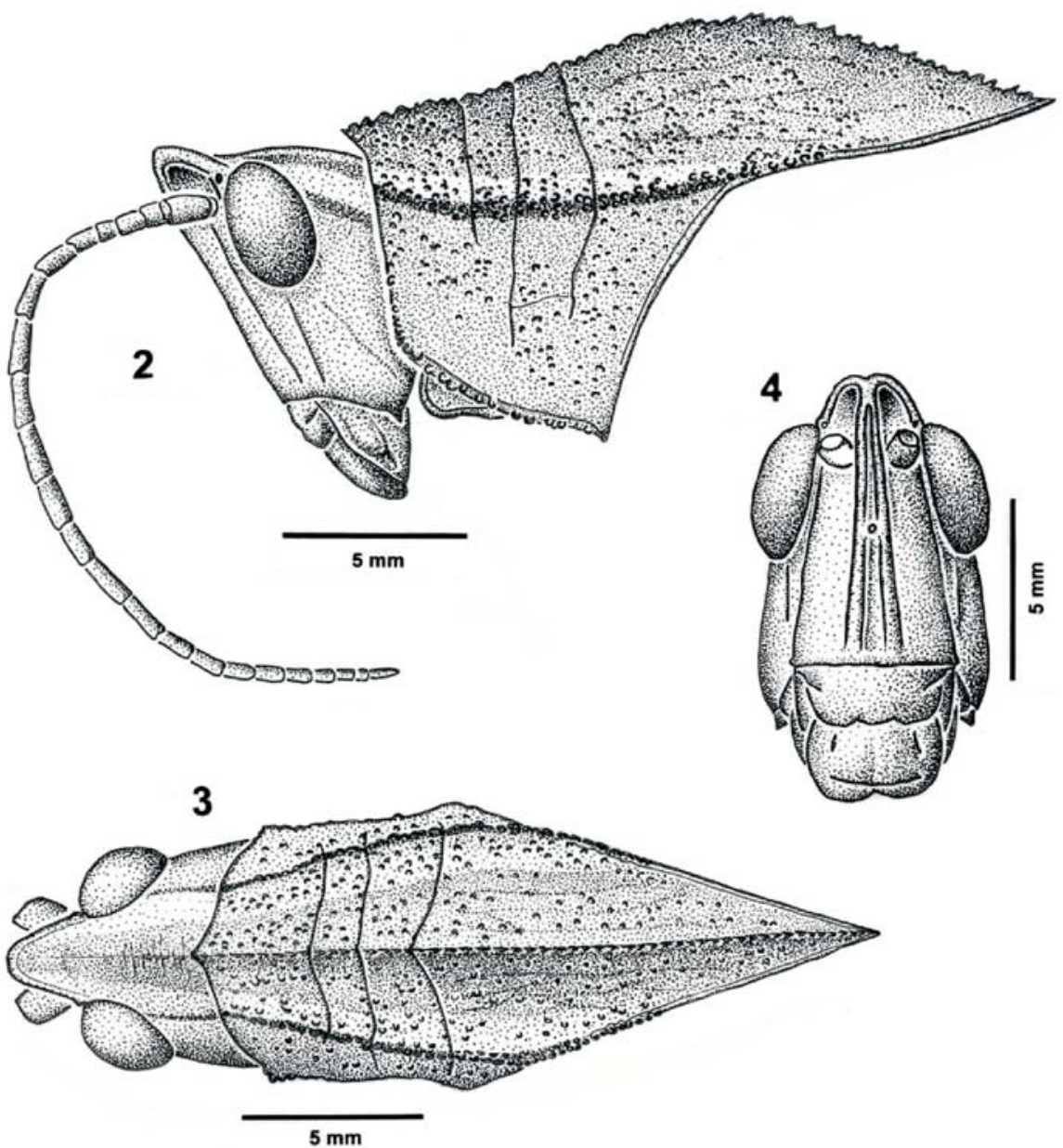

5

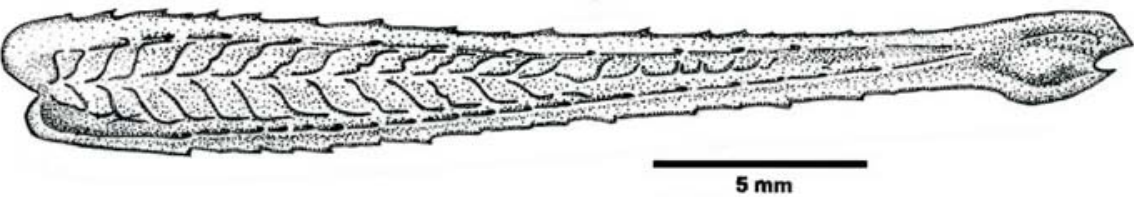

Figs. 2-5. Prionolopha serrata (Linnaeus, 1758), ơ: 2, cabeça + pronoto, lateral; 3, cabeça + pronoto, dorsal; 4, cabeça, frontal; 5, fêmur posterior, face externa.

subocular. Em vista frontal (fig. 4), costa frontal côncava, com margens subparalelas, divergentes do fastígio ao clípeo.

Tórax, dorsalmente (fig. 3), com o disco granulosopontuado, estreito, com ângulo cefálico não alcançando a margem posterior dos olhos. Sulcos anterior e médio paralelos e mais próximos que o médio e o principal, os quais são divergentes no sentido das carenas laterais. Em vista lateral (fig. 2), metazona com nervação longitudinal e transversal. Carena média com altura máxima no plano do ângulo umeral. Lobo lateral com margem anterior reta, granulosa na metade inferior; margem externa curva, elevada anteriormente e granulosa; margem posterior curva, obsoleta e lisa. Tégminas ultrapassam o ápice do fêmur posterior. Asas membranosas hialinas, menores que as tégminas, com aparelho estridulatório. Fêmures anterior e médio delgados e cilíndricos. Fêmur posterior (fig. 5) delgado, ultrapassando o ápice do abdome.

Terminália, em vista dorsal (fig. 6), com epiprocto triangular. Em vista lateral (fig. 7), cercos cônicos, curtos, com ápice arredondado, alcançando um terço do comprimento dos paraproctos. Placa subgenital cônica, triangular e com ápice elevado. Epífalo, em vista dorsal (fig. 10), com ponte estreita. Âncoras ultrapassando o ápice das projeções anteriores. Lophi elevado, subcônico e esclerosado. Em vista lateral (fig. 11), lophi $2 \mathrm{x}$ mais alto que a margem superior da âncora. Em vista frontal (fig. 9), lophi triangular. Ponte com margem dorsal sub-reta e ventral lobada medianamente. Cingulum (figs. 12, 13) com apódemas projetados anteriormente e largos, com área mediana membranosa. Em vista lateral, com rami largos e margem póstero-ventral projetada medianamente. Endofalo (figs. 14-17) com valvas dorsais muito 

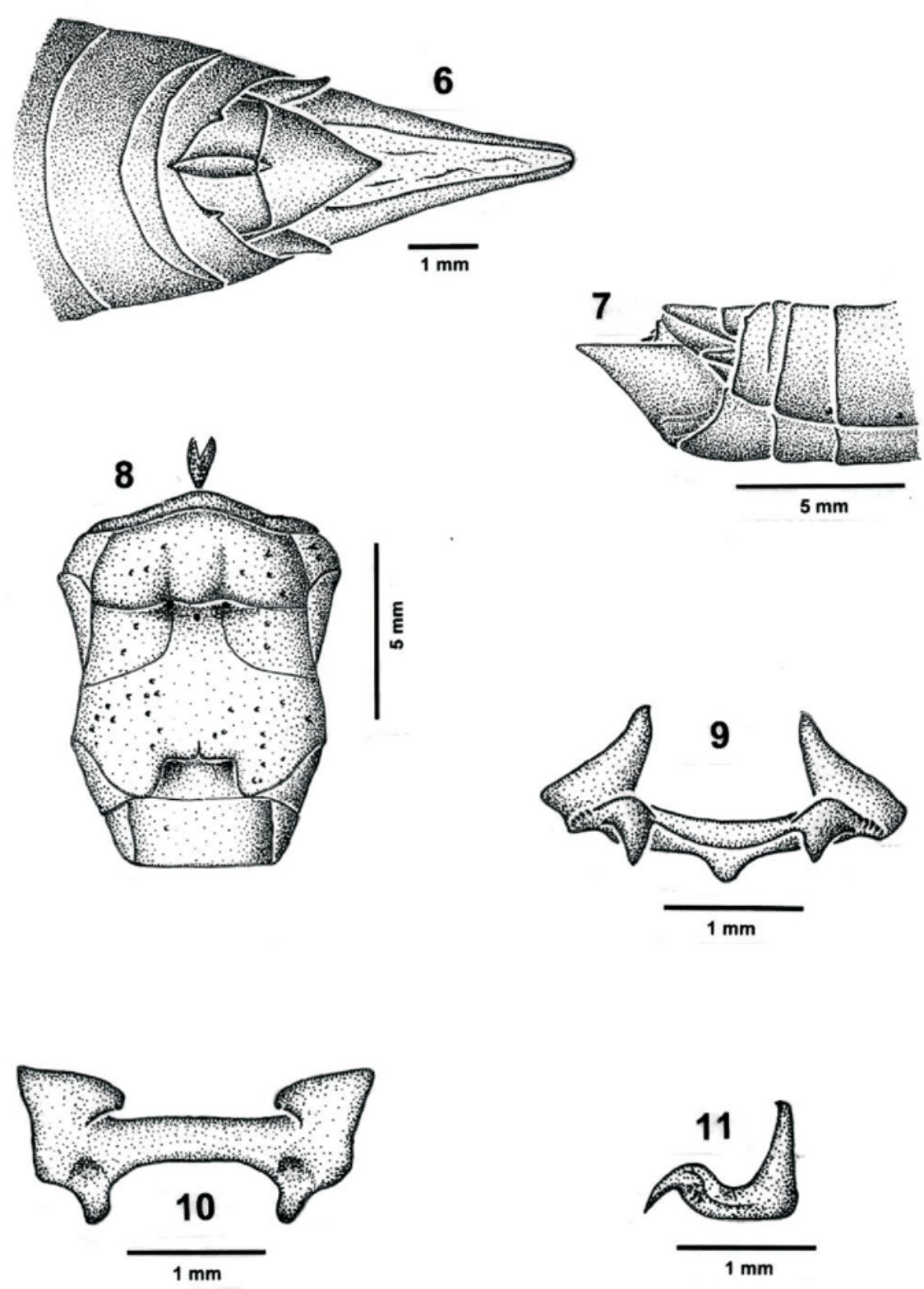

Figs. 6-11. Prionolopha serrata (Linnaeus, 1758), ơ: 6, terminália, dorsal; 7, terminália, lateral; 8, protórax, ventral; 9, epífalo, frontal; 10, epífalo, dorsal; 11, epífalo, lateral.

esclerosadas, margem dorsal com cristas subparalelas do ápice até próximo ao cingulum e faces internas côncavas. Gonapófise curta e oblíqua. Valvas ventrais obsoletas, membranosas.

Coloração verde-pálida a verde-musgo. Faixas amarelas dorsolaterais estendidas longitudinalmente da margem externa do fastígio ao campo anal das tégminas, margeando internamente as carenas laterais do disco, sendo flanqueadas externamente por estreitas linhas escuras de mesma extensão. Carenas laterais escuras. Fêmur posterior de padrão cromático semelhante ao restante do corpo. Espinhos da carena média e carínula superior com mesmo padrão de verde; espinhos das tíbias com ápices escuros e bases claras.

Fêmeas. Maiores e mais robustas (fig. 28) que os machos. Terminália, em vista dorsal (fig. 21), com epiprocto triangular e margem caudal mais arredondada. Em vista lateral (fig. 22), epiprocto mais longo que os paraproctos, cercos curtos e cônicos, alcançando $3 / 4$ do comprimento dos paraproctos. Valvas dorsais com mesmo comprimento das ventrais. Em vista ventral (fig. 23), placa subgenital com guia de ovos mais longa que os lobos laterais. Espermateca (fig. 25) com divertículo pré-apical longo, espiralado. Divertículo apical reduzido.

Coloração verde, com uma faixa amarela ou vermelha nas margens dorsais externas do disco ou sem faixa. Quando presentes, as faixas estendem-se do fastígio ao campo anal das tégminas, sendo margeadas externamente por linha castanho-escura. Lobo lateral do pronoto com margens anterior e exterior amarelo-claras. Nas fêmeas com faixa vermelha, a área marginal superior externa e interna do fêmur posterior podem ser igualmente avermelhadas, dentes da carena superior com ápice avermelhado. Carenas e carínulas 


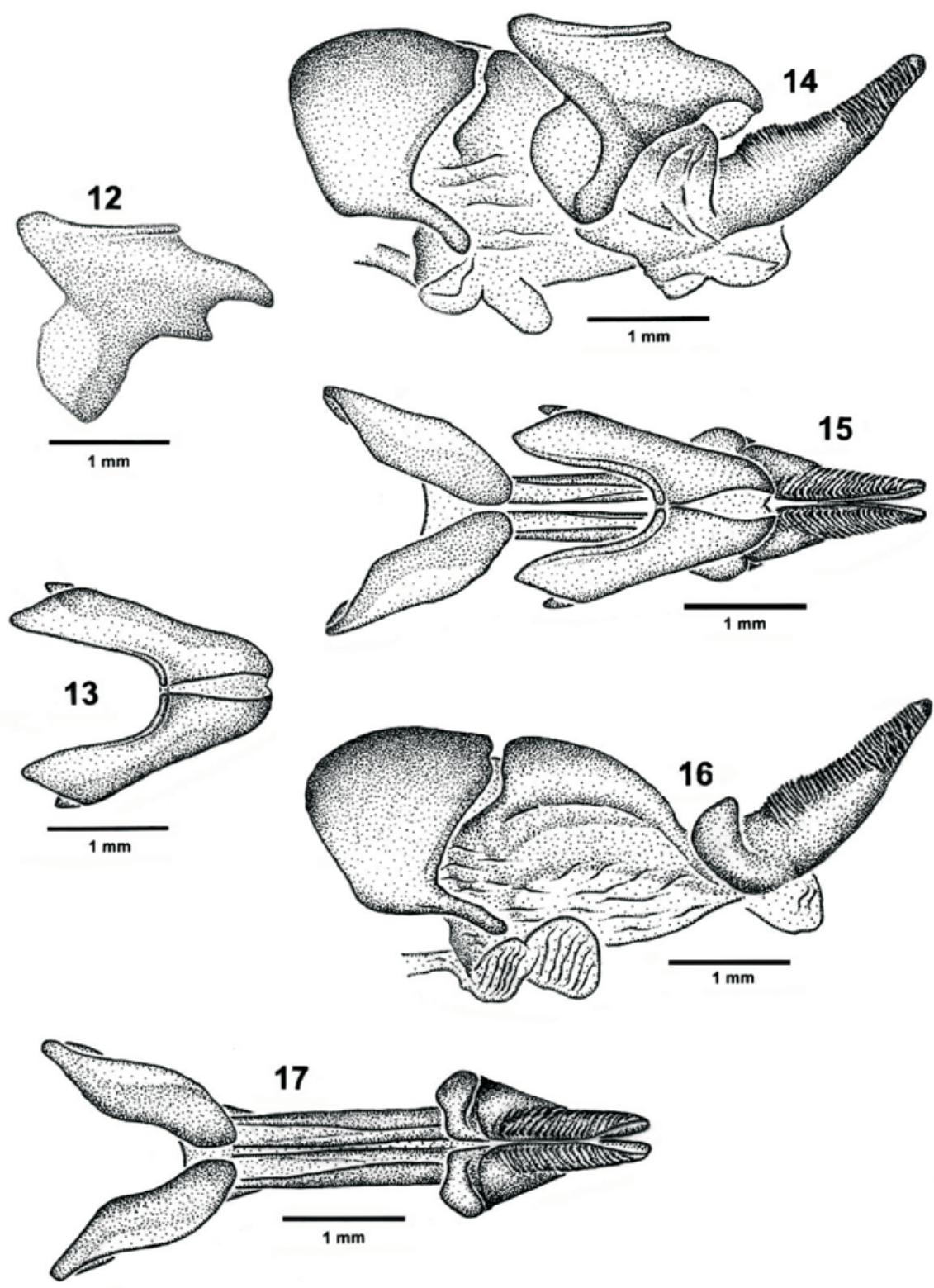

Figs. 12-17. Prionolopha serrata (Linnaeus, 1758), o: 12, cingulum, lateral; 13, cingulum, dorsal; 14, complexo fálico, sem epífalo, lateral; 15, complexo fálico, sem epífalo, dorsal; 16, complexo fálico, sem cingulum, lateral; 17, complexo fálico, sem cingulum, dorsal.

do fêmur posterior com dentes avermelhados em diversas fêmeas, independentemente da coloração das mesmas.

Medidas em milímetros. (A) comprimento da costa frontal ao ápice da tégmina: ơ 39,0-53,0, $\$ 67,0-80,0$; (B) comprimento da costa frontal ao ápice do abdome: $\sigma^{7}$ $36,0-45,0,965,0-76,0 ;(\mathrm{C})$ comprimento da costa frontal à margem anterior dos olhos, em vista dorsal (fastígio): 2,0, \& 2,0-3,0; (D) prozona: ơ 4,0-6,0, \& 7,0-10,0; (E) metazona: $9,0-12,0, \$ 17,0-22,0 ;(\mathrm{F})$ pronoto: $14,0-18,0$, \& 24,0-32,0; (G) comprimento cabeça + pronoto: 22,0, $931,0-37,0 ;(\mathrm{H})$ comprimento do fêmur posterior: $₫$ 21,0-26,0, 32,0-40,0; (I) comprimento da tégmina $\sigma^{2} 35,0-$ 40,0, §47,5-57,0; (J) maior diâmetro do olho: ơ 3,0-3,5, \& 4,0; (K) menor diâmetro do olho: ơ2,0, 2,0-2,5; (M) largura do espaço interocular: o 2,0, $\$ 3,0-4,0 ;(\mathrm{N})$ largura da cabeça na área dos olhos: $75,5-6,0, \uparrow 7,5-8,5 ;(\mathrm{O})$ largura da cabeça na área das genas; $\circlearrowleft 5,5, \$ 8,5-10,0 ;(\mathrm{P})$ largura máxima do disco: $\checkmark 6,5, \$ 9,5-11,5 ;(\mathrm{Q})$ largura máxima do fêmur posterior: $\sigma^{\Im} 3,0-4,0, \nsubseteq 4,5-5,5$; (R) maior altura do pronoto: $3,0-4,0, \$ 5,0-7,0$; (S) maior altura do lobo lateral do pronoto: o $5,0-6,0$, , 10,0.

Material examinado. BRASIL, Amazonas: Benjamin Constant, 19 ơ, 4 \&, VIII.1977-IX.1979, B. Silva col.; 7 ơ, \&, IX.1977-VIII.1978, I. C. Lima col.; Manaus (Igarapé Bolívia), 3 ơ, 2 \& (1 ninfa), V.1979, B. Silva col.; Tabatinga, 10 o', 3 \&, X.1977-XII.1977, L. G. Pereira col.; 65 o, 40 \&, XII.1977IV.1979, B. Silva col.; Pará: Belém (Mocambo), 2 đ, 2 \&, IV.1978, B. Silva col.; Óbidos, 19 ơ, 11 \&, IV.1978-VII.1978, B. Silva col.; Oriximiná, 2 † (1 ninfa), IV.1978, B. Silva col.; Rondônia: 

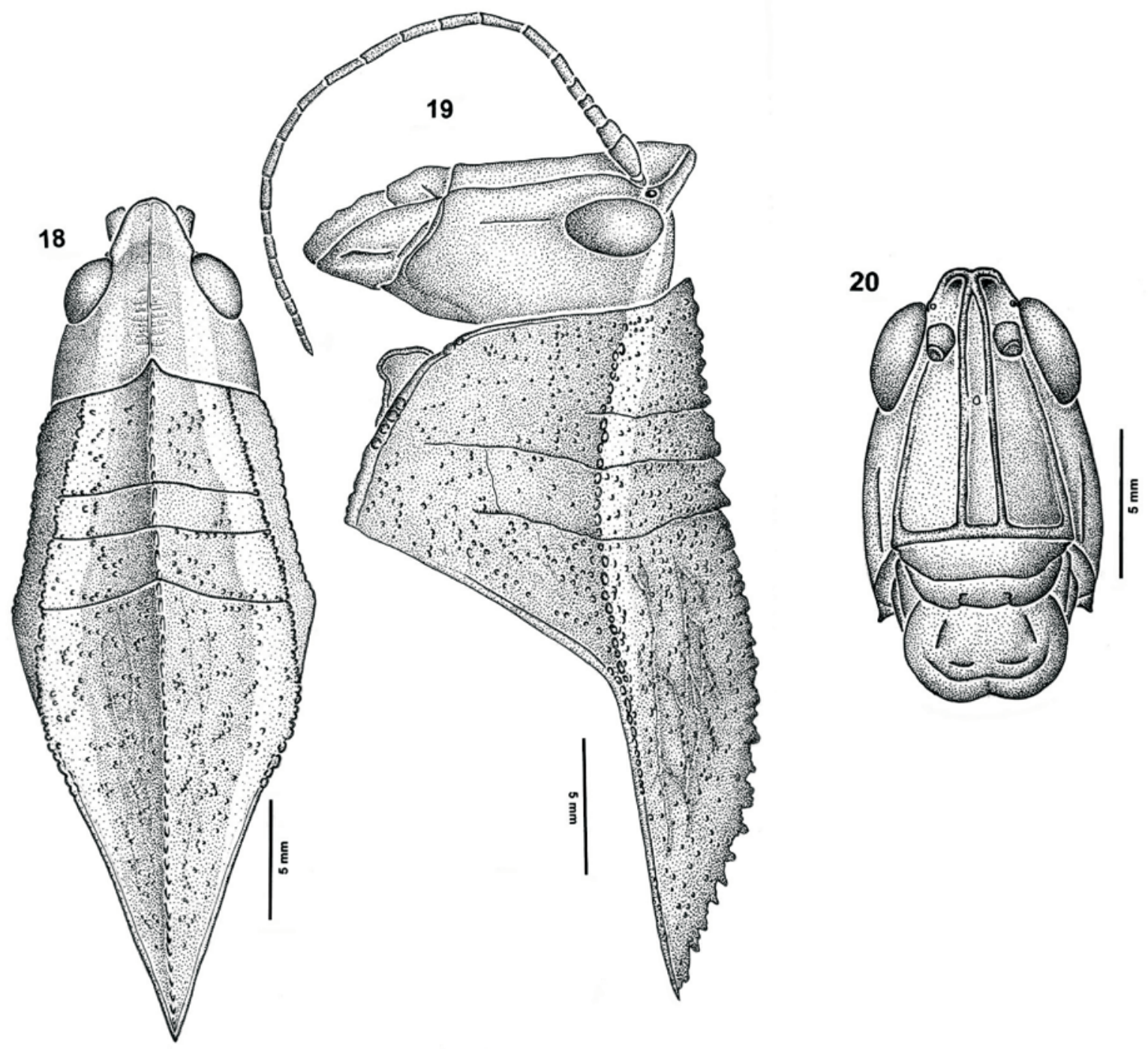

21

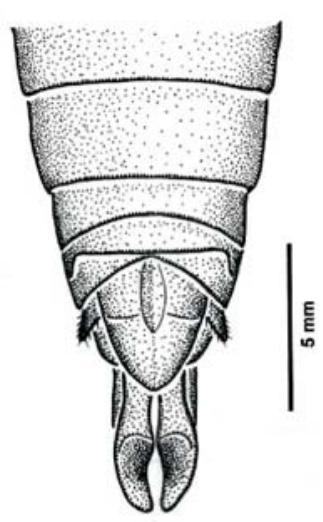

22

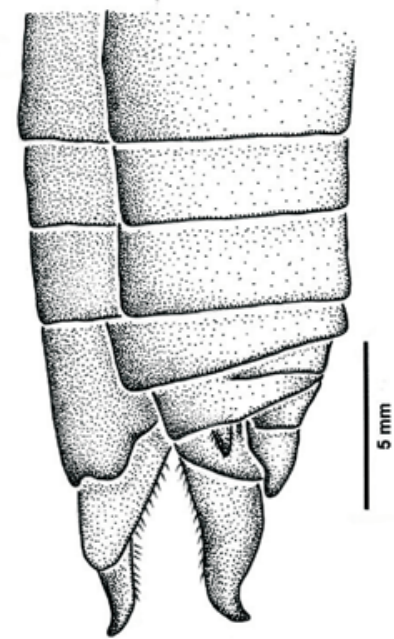

23

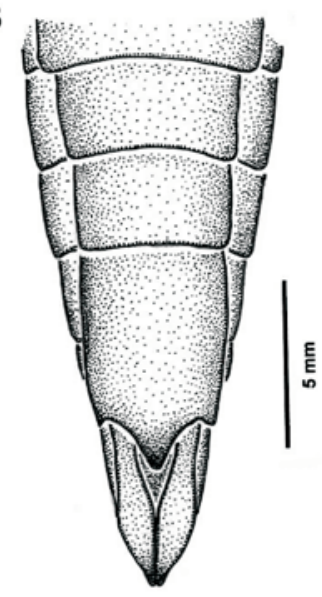

Figs. 18-23. Prionolopha serrata (Linnaeus, 1758), ł: cabeça + pronoto: 18, dorsal; 19, lateral; 20, cabeça, frontal; 21, terminália, dorsal; 22, terminália, lateral; 23, terminália, ventral. 


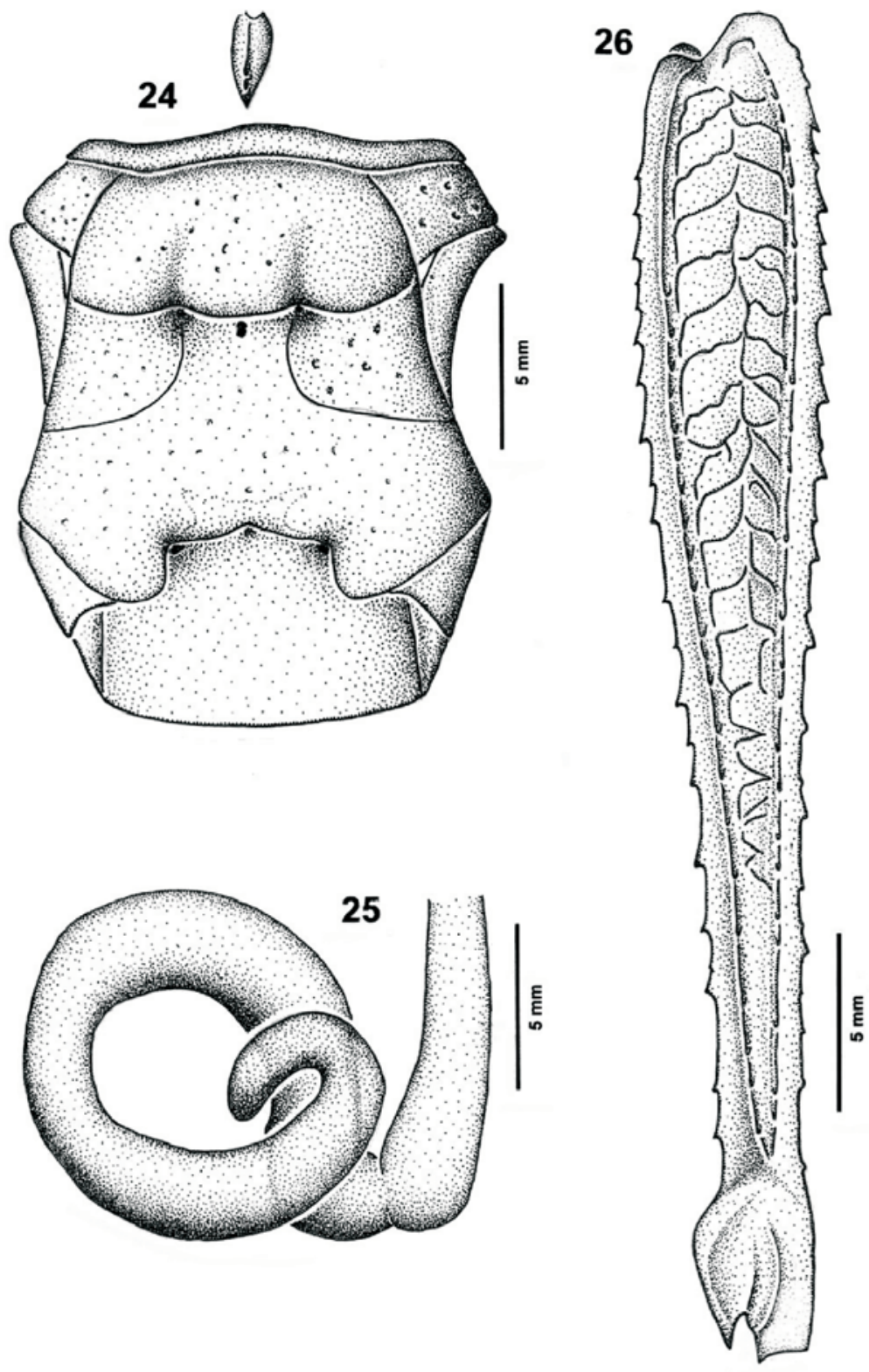

Figs. 24-26. Prionolopha serrata (Linnaeus, 1758), ̨: 24, tórax, ventral; 25, espermateca; 26, fêmur posterior, face externa.

Ariquemes, $\sigma^{\prime}$ (ninfa), XI.1979, J. Becker, B. Silva \& O. Roppa col.; Cachoeira Santo Antônio, 3 ơ, XII.1978, E. S. Lima col.; Cachoeira do Samuel, II.1978, B. Silva col., 5 oै, 2 \%; Ouro Preto d'Oeste, 4 đ', 2 \&, X.1980-XI.1983, J. Becker, B. Silva \& O. Roppa col.; Porto Velho, 9 o, 1\%, XII.1977-XII.78, E. S. Lima col.; 5 đ, I.1978-V.1978, M. Souza col.; 20 ठ, 6 क, II.1978III.1979, B. Silva col.; Vilhena, , X.1979, J. Becker, B. Silva \& O. Roppa col.; Mato Grosso: Diamantino, 9 o', III.1979, B. Silva col.; BR 163 (Alto rio Arinos), 7 ơ, 2 \&, III.1979, B. Silva col.; 400m, ठ․ II.1981, M. Alvarenga col.; Rondonópolis (40 Km SE), హ, III.1980, H. R. Robert, O. Roppa \& C. S. Carbonell col.; Mato Grosso do Sul: $30 \mathrm{Km}$ E de Aquidauana, ơ, 16.III.1980, H. R. Robert, O. Roppa e C. S. Carbonell col.

Material-tipo. Holótipo fêmea depositado no LSUK (não examinado).

\section{Securigera Bolívar, 1909}

Securigera Bolívar, 1909:343; Amedegnato, 1977:87; CARBonell, 1986:371
Espécie-tipo: Securigera acutangula Bolívar, 1909, por monotipia [= Alcamenes cristatus Bruner, 1906]

Porte médio a grande. Braquípteros, com asas alcançando os tergitos 3 a 8. Comprimento dos machos 31,5 a 33,0 mm e das fêmeas 33,0 a 41,5 mm.

Corpo comprimido lateralmente (figs. 30, 45). Fastígio do vértice subtriangular, com margem anterior subaguda. Pronoto estreito e tectiforme, com carenas laterais subparalelas, curvas, subcrenuladas até o ângulo umeral, com maior distância na metazona. Disco com margens posteriores retas, lisas, com ângulo caudal ultrapassando a inserção do fêmur posterior. Em vista lateral (figs. 29, 46), fastígio do vértice reto. Vértice acentuadamente convexo, com plano tangente acima da margem anterior do fastígio. Carena média elevada, lisa ou serrilhada no terço posterior, com curvatura uniforme e altura máxima na metazona. Carenas laterais retas. Disco com margem externa crenulada, curva, elevada anteriormente. 

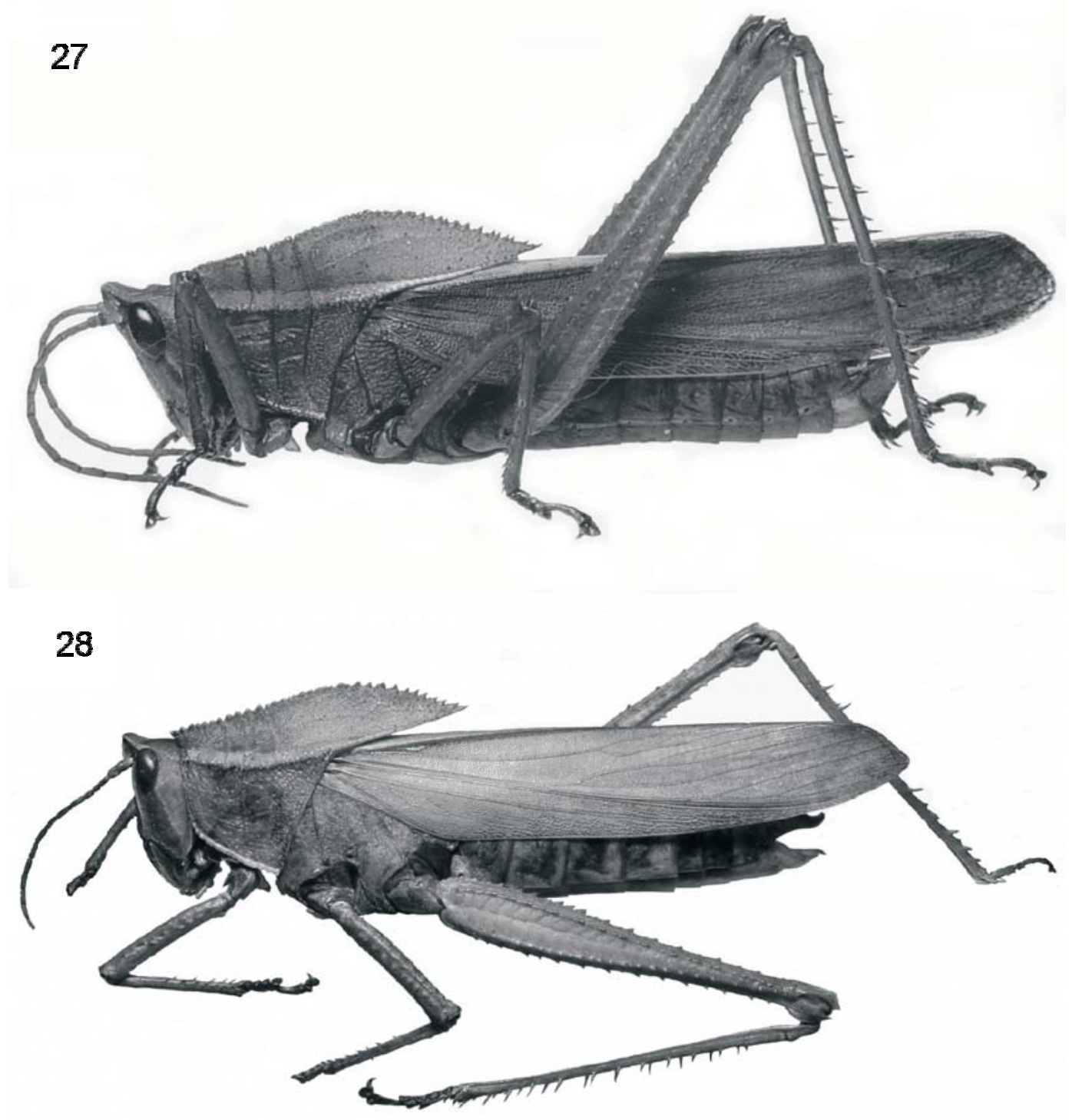

Figs. 27, 28. Prionolopha serrata (Linnaeus, 1758): 27, O', espécime de Benjamin Constant, Amazonas, Brasil, comprimento, 52 $\mathrm{mm} ; 28$,, , mesma procedência,comprimento, $70 \mathrm{~mm}$.

Tégminas (figs. 54, 55) curtas, subtriangulares ou lanceoladas, alcançando do $2^{\circ}$ ao $8^{\circ}$ tergito nos machos e $10^{\circ}$ nas fêmeas. Fêmur posterior (figs. 32,48 ) com carenas superior e inferior serrilhadas, com dentes pequenos e esparsos.

\section{Securigera cristata (Bruner, 1906) comb. nov. (Figs. 29-56)}

Alcamenes cristatus BRUNER, 1906b:650

Securigera acutangula Bolívar, 1909:345; Mesa et al., 1983:516 (cariol.). Syn. nov.

Macho. Cabeça, em vista dorsal (fig. 30), tão larga quanto a distância entre as margens exteriores dos lobos do pronoto. Fastígio sem crista arqueada. Vértice com crista média estendendo-se da margem anterior do fastígio à margem anterior do pronoto; cristas transversais curtas, obsoletas, dispostas da margem anterior dos olhos ao ângulo cefálico do disco. Olhos pequenos, com espaço interocular menor que o comprimento do fastígio. Em vista lateral (fig. 29), com costa frontal reta e oblíqua. Em vista frontal (fig. 31, 47), com costa frontal de margens divergentes no sentido ventral e obsoletas do ocelo médio para baixo.

Tórax, em vista dorsal (fig. 30), com pronoto tectiforme e superfície granulosa-pontuada. Disco estendendo-se do vértice até o primeiro quinto do fêmur posterior (fig. 54), com ângulo cefálico próximo à margem posterior dos olhos e ângulo caudal agudo. Carena média marcada por três sulcos pouco profundos que se estendem até as carenas laterais. Sulco anterior convergente em relação ao médio e principal divergente em relação ao mesmo. Carenas laterais subparalelas, lisas até o sulco médio, rugosas até o ângulo umeral. Em vista lateral (fig. 29), metazona provida de nervuras longitudinais obsoletas e ramificadas. Carena média muito 

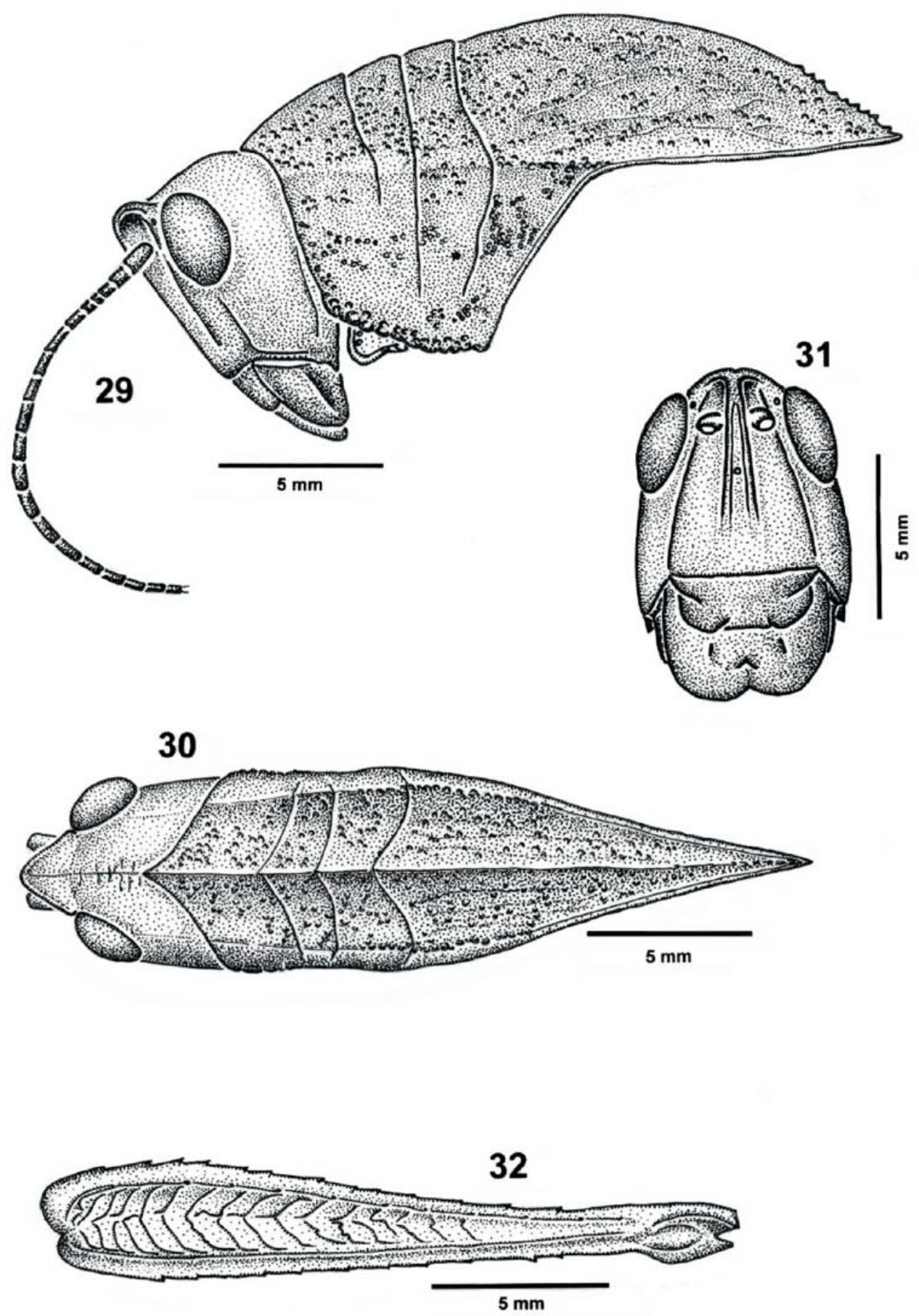

Figs. 29-32. Securigera cristata (Bruner, 1906) comb. nov., o: 29, cabeça + pronoto, lateral; 30, cabeça + pronoto, dorsal; 31, cabeça, frontal; 32, fêmur posterior, face externa.

elevada, com curvatura uniforme e máxima altura no plano do ângulo umeral. Carena lateral no mesmo plano da margem posterior do disco. Carena média integralmente lisa ou denteada no terço posterior. Lobo lateral com margens anterior lisa e reta, externa granulosa e oblíqua e posterior lisa, sub-reta. Tégmina (figs. 54, 55) curta, com ápice agudo, alcançando a segunda metade do fêmur posterior. Fêmur posterior (fig. 32) delgado, ultrapassando o ápice do abdome (fig. 54).
Terminália, em vista dorsal (fig. 34), com cercos cônicos, curtos e ápice arredondado. Em vista lateral (fig. 33), placa subgenital cônica, voltada para cima e cercos que alcançam um terço do comprimento dos paraproctos. Epífalo, em vista dorsal (fig. 36), com ponte estreita, dilatada medianamente. Âncora projetada anteriormente. Lophi cônicos, ápice arredondado, com margem anterior rugosa, posterior lisa. Em vista lateral (fig. 38), âncora com altura subigual ao lophi. Em vista frontal (fig. 37), 

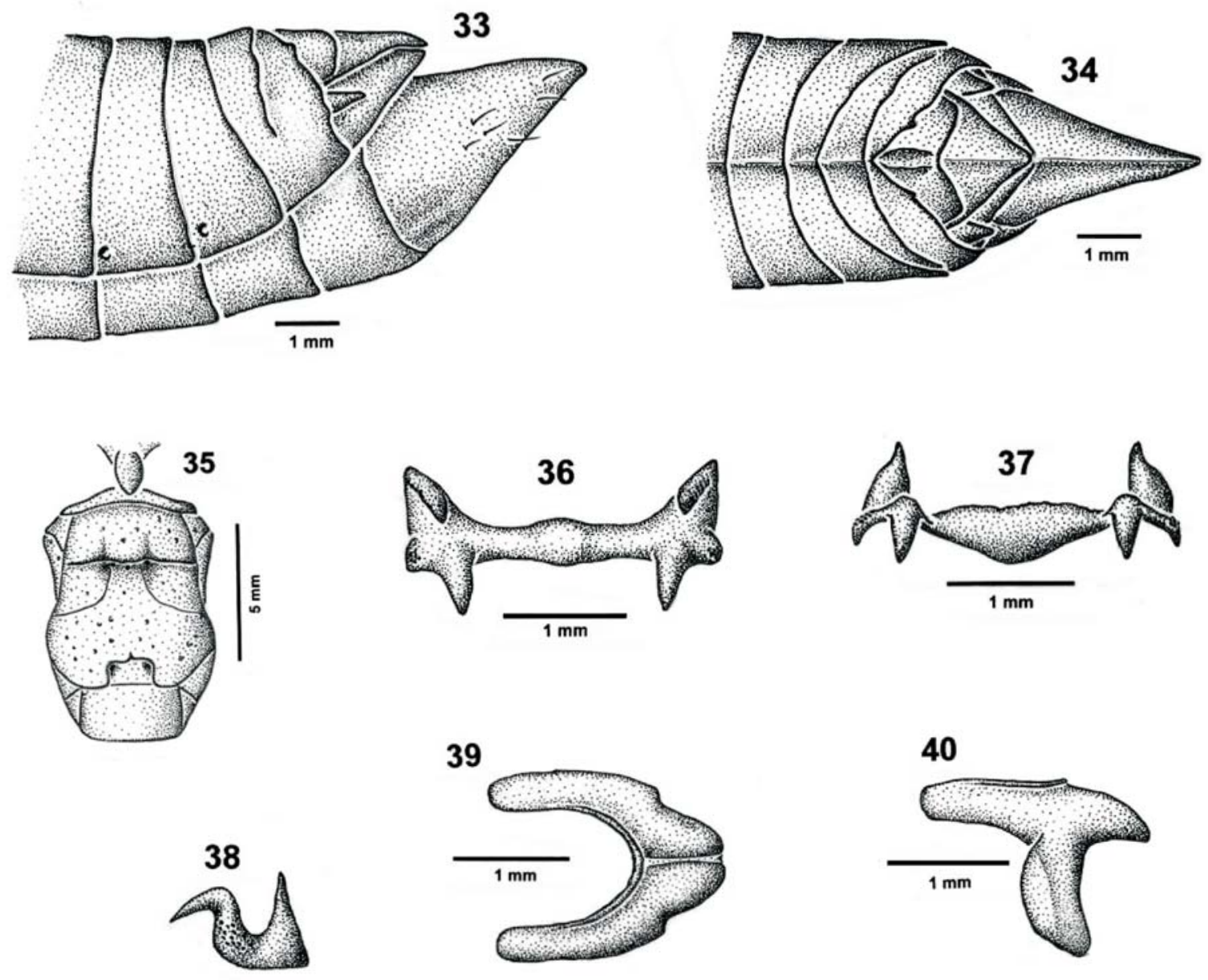

39
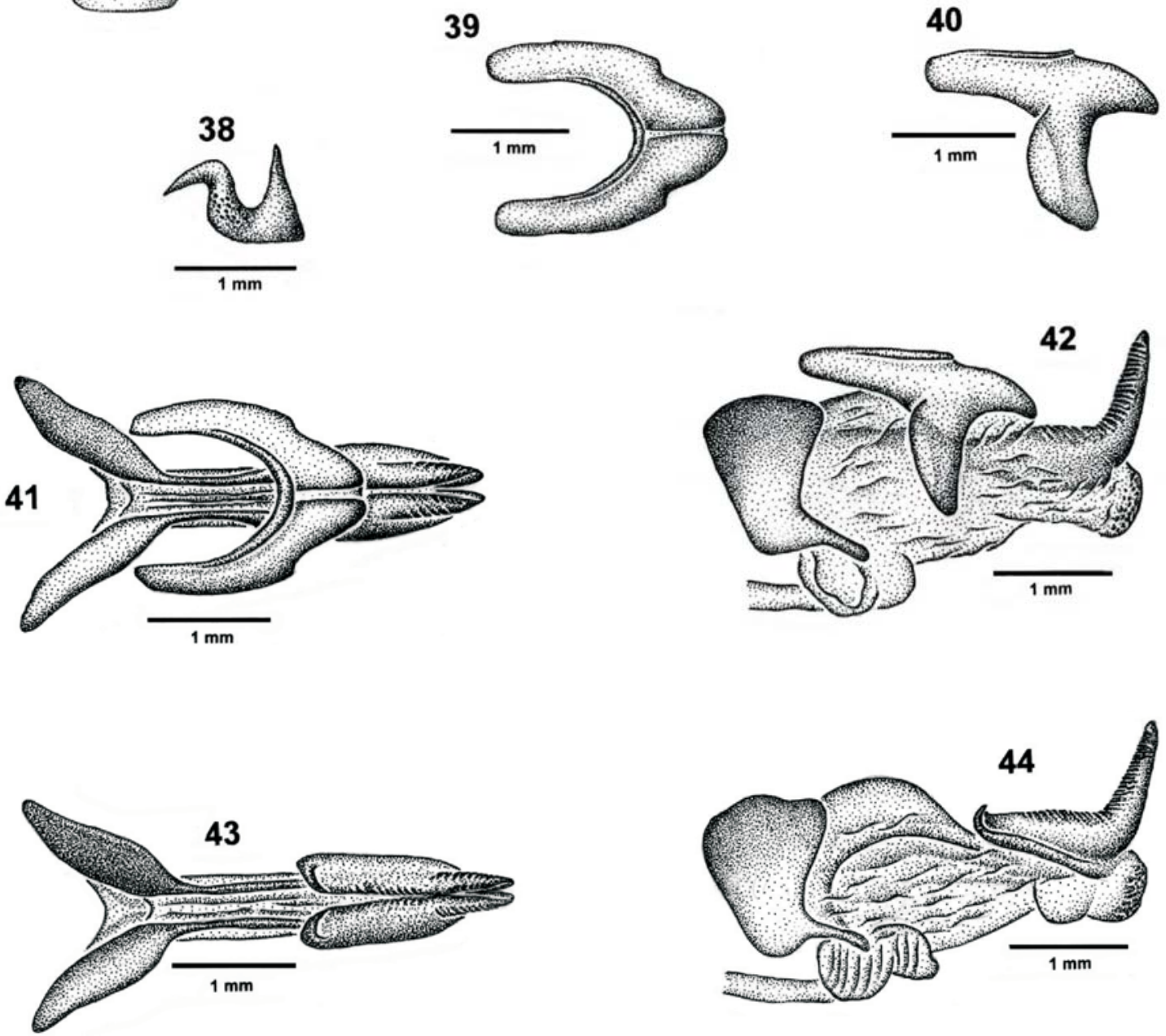

Figs. 33-44. Securigera cristata (Bruner, 1906) comb. nov., ơ: 33, terminália, lateral; 34, terminália, dorsal; 35, tórax, ventral; 36, epífalo, dorsal: 37, epífalo, frontal; 38, epífalo, lateral; 39, cingulum, dorsal; 40, cingulum, lateral; 41, complexo fálico sem epífalo, dorsal; 42, complexo fálico sem epífalo, lateral; 43, complexo fálico, sem cingulum, dorsal; 44, complexo fálico, lateral. 

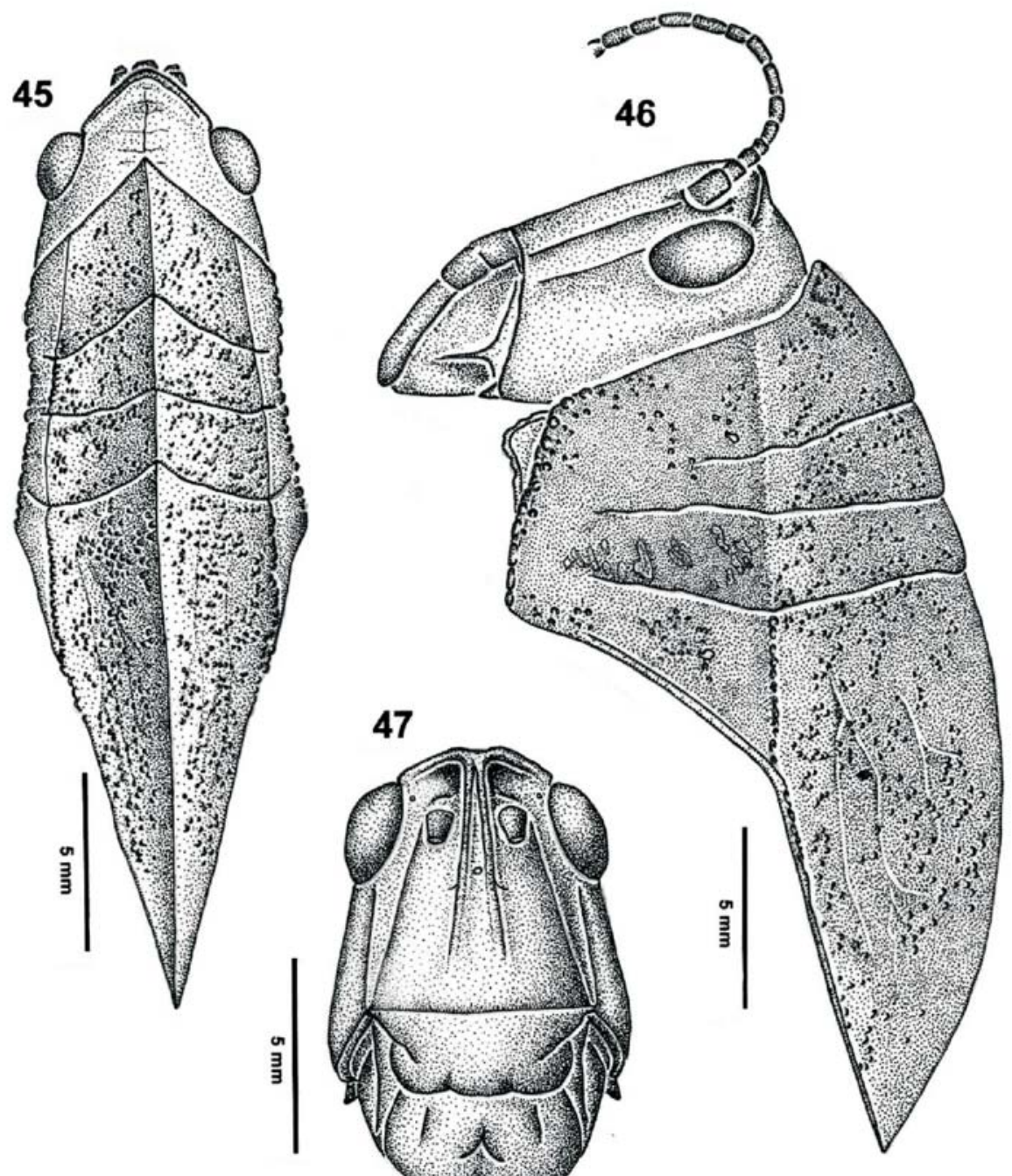

\section{8}

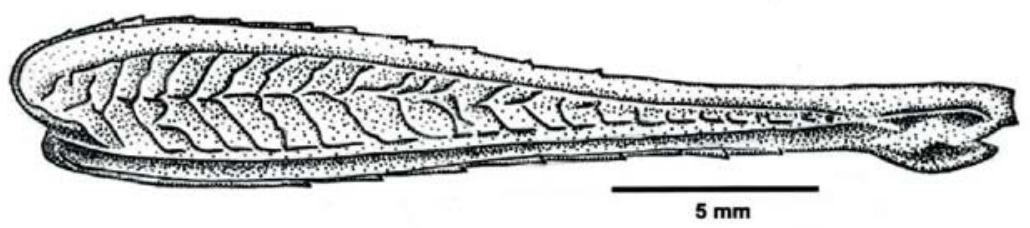

Figs. 45-48. Securigera cristata (Bruner, 1906) comb. nov., f: 45, cabeça + pronoto, dorsal; 46, cabeça + pronoto, lateral; 47, cabeça, frontal; 48, fêmur posterior, face externa.

ponte com margem dorsal sub-reta e irregular, ventral curva e lisa, dilatada medianamente. Cingulum (figs. 39, 40) com apódemas projetados anteriormente e ápice curvo; em vista dorsal medianamente incompleto e estreito. Zigoma com margem caudal curva. Rami projetados ventralmente, margens cefálica e caudal curvas. Endofalo (figs. 41, 43) com valvas dorsais paralelas, ápices divergentes e côncavas internamente. Em vista lateral (figs. 42, 44), valva dorsal esclerosada, subcônica, dobrada para cima em ângulo subigual a $90^{\circ}$. Margem dorsal com cristas obsoletas, subparalelas, dispostas do ápice ao bordo cefálico das valvas. Valva ventral obsoleta. Saco ejaculatório desenvolvido e duto espermático estreito. Gonapófise longa, estreita e projetada obliquamente.

Coloração verde; margens do fastígio castanhoescuras. Disco do pronoto e lobos laterais com raras máculas de tonalidade escuras. Margem exterior do lobo lateral e face superior do fêmur posterior castanhoescuros.

Fêmeas. Maiores e mais robustas (fig. 55). Carena média lisa ou serrilhada no terço posterior.

Terminália (figs. 50-52) com epiprocto triangular, cercos curtos e cônicos alcançando um quarto dos 

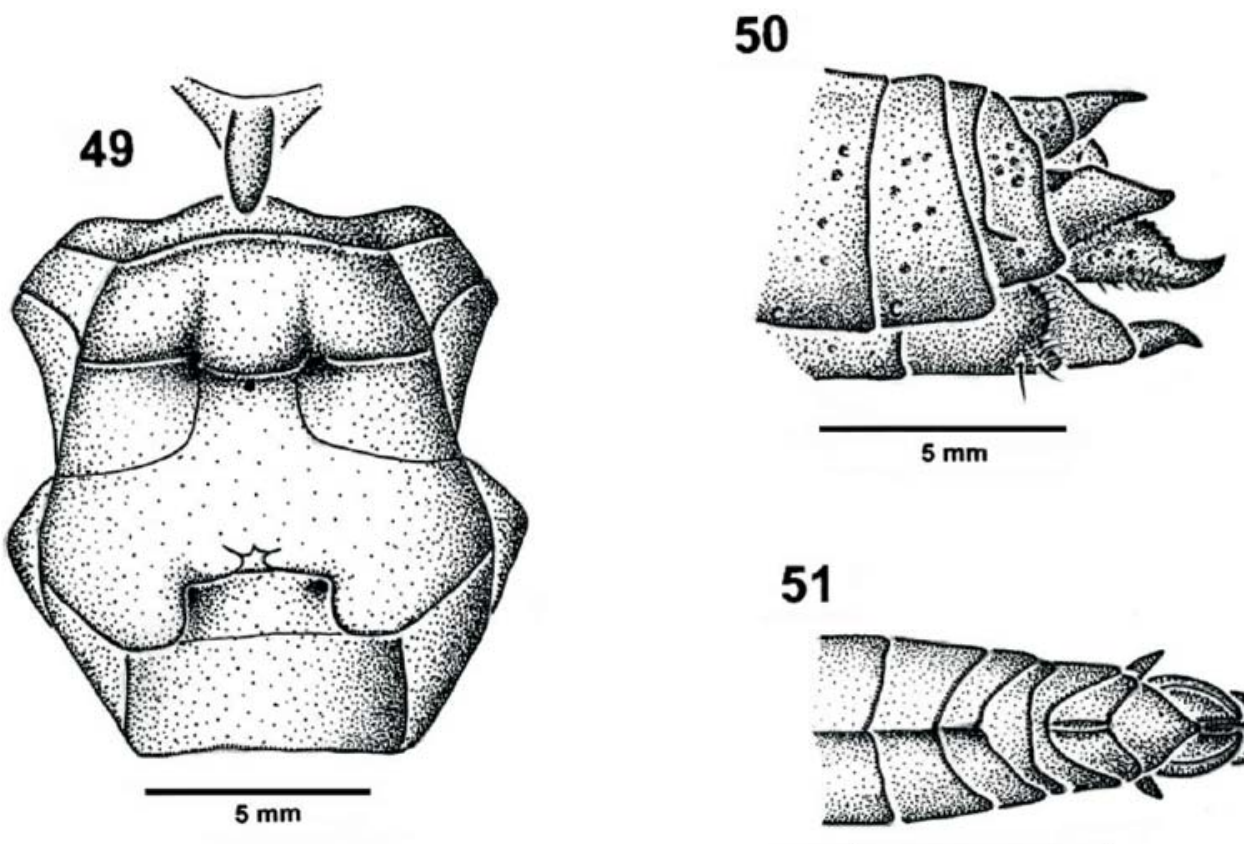

\section{1}
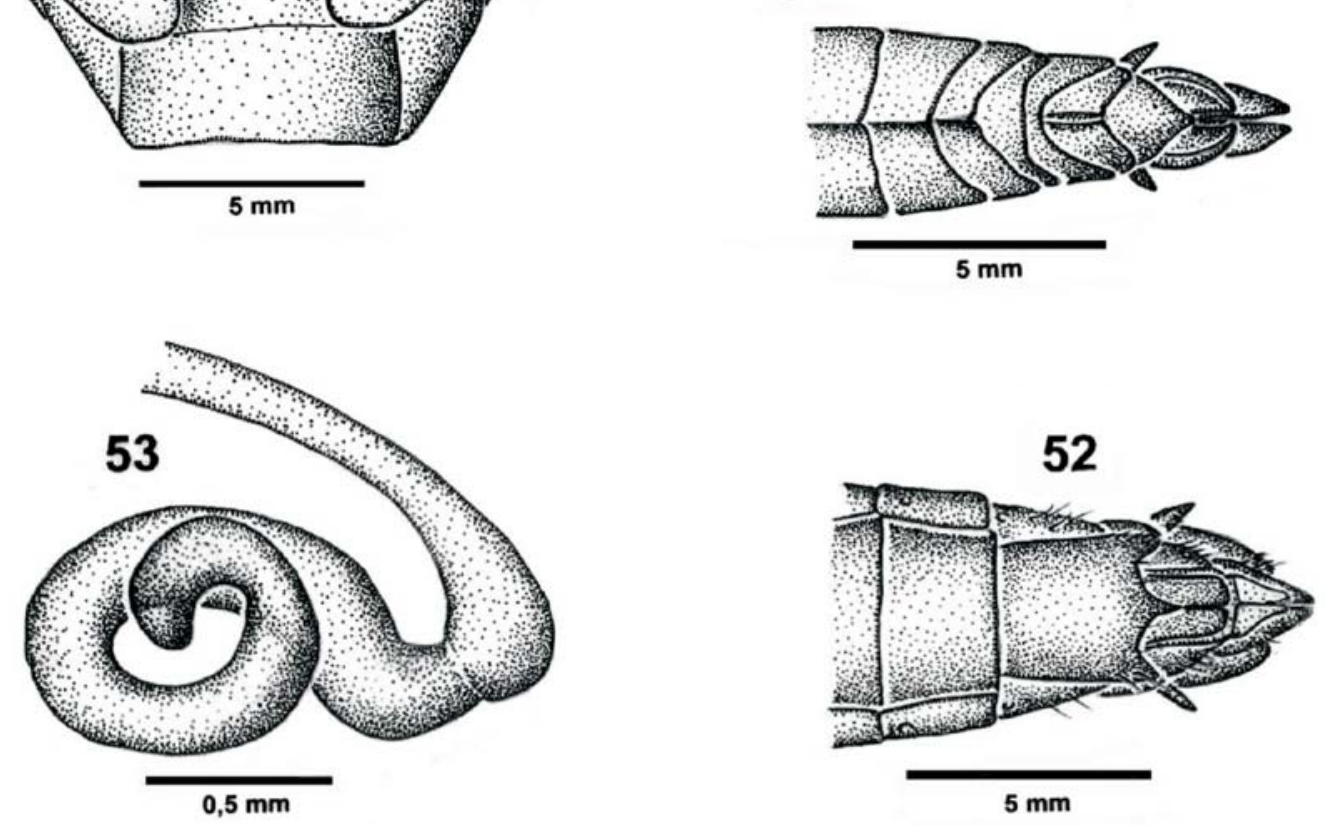

Figs. 49-53. Securigera cristata (Bruner, 1906) comb. nov., @: 49, tórax, ventral; 50, terminália, lateral; 51, terminália, dorsal; 52, terminália, ventral; 53, espermateca.

paraproctos. Valvas ventrais do ovipositor menores que as dorsais. Guia de ovos pouco mais longa que os lobos laterais da placa subgenital. Espermateca (fig. 53) com divertículo apical curto e arredondado; divertículo préapical espiralado, longo.

Padrão cromático semelhante aos machos.

Material-tipo. Holótipo macho depositado no UCME (não examinado).

Medidas em milímetros. (A) comprimento da costa frontal ao ápice da tégmina: o 31,5-33,0, \&33,0-41,5; (B) comprimento da costa frontal ao ápice do abdome: o 35,5-37,5, $, 45,5-48$; (C) comprimento da costa frontal à margem anterior dos olhos em vista dorsal (fastígio): 8 1,4-1,6, § 1,8-2,0; (D) prozona: o 6,0-6,1, 7,0-9,0; (E) metazona: o 13,0-15,0, \&13,0-15,5; (F) pronoto: o 19,0-
$21,0, \subsetneq 20,0-24,3 ;(\mathrm{G})$ comprimento cabeça + pronoto: $\circlearrowleft$ 22,0-25,0, 24,0-27,5; (H) comprimento do fêmur posterior: o 20,0-21,0, $\$ 23,5-24,5$; (I) comprimento da tégmina $\$ 19,5-$ 20,0, § 19,0-26,5; (J) maior diâmetro do olho: o 3,0-3,2, ๆ 3,0; (K) menor diâmetro do olho: ơ 2,0, \& 1,7-2,0; (M) distância do espaço interocular: o 2,4-2,6, $₫ 3,3-3,7$; (N) largura da cabeça na área dos olhos: o 2,4-2,6, \& 3,4-3,6; (O) largura da cabeça na área das genas; $₫ 6,0, \subsetneq 7,0-7,5$; (P) largura máxima do disco: $\$ 5,0-6,0, \uparrow 6,0-7,0 ;(\mathrm{Q})$ largura máxima do fêmur posterior: $33,5-4,0, \varsubsetneqq 4,0 ;(\mathrm{R})$ maior altura do pronoto: $\checkmark 4,5-5,0, \$ 5,0-5,6 ;(\mathrm{S})$ maior altura do lobo lateral do pronoto: $\$ 5,5, \subsetneq 7,0-7,2$.

Material examinado. BRASIL, Mato Grosso do Sul: Perdidos, Porto Murtinho, 2 ơ, 22.I.1954, L. Portella col.; Bonito, §, \&, 12.I.1954, L. Portella col. PARAGUAI, Caaguazú: $40 \mathrm{Km} \mathrm{N}$ de Caaguazú (Ruta Caaguazú-Yhú), 2 \&, 13.III.1965, C. S. Carbonell, A. Mesa \& M. A. Monné col. 


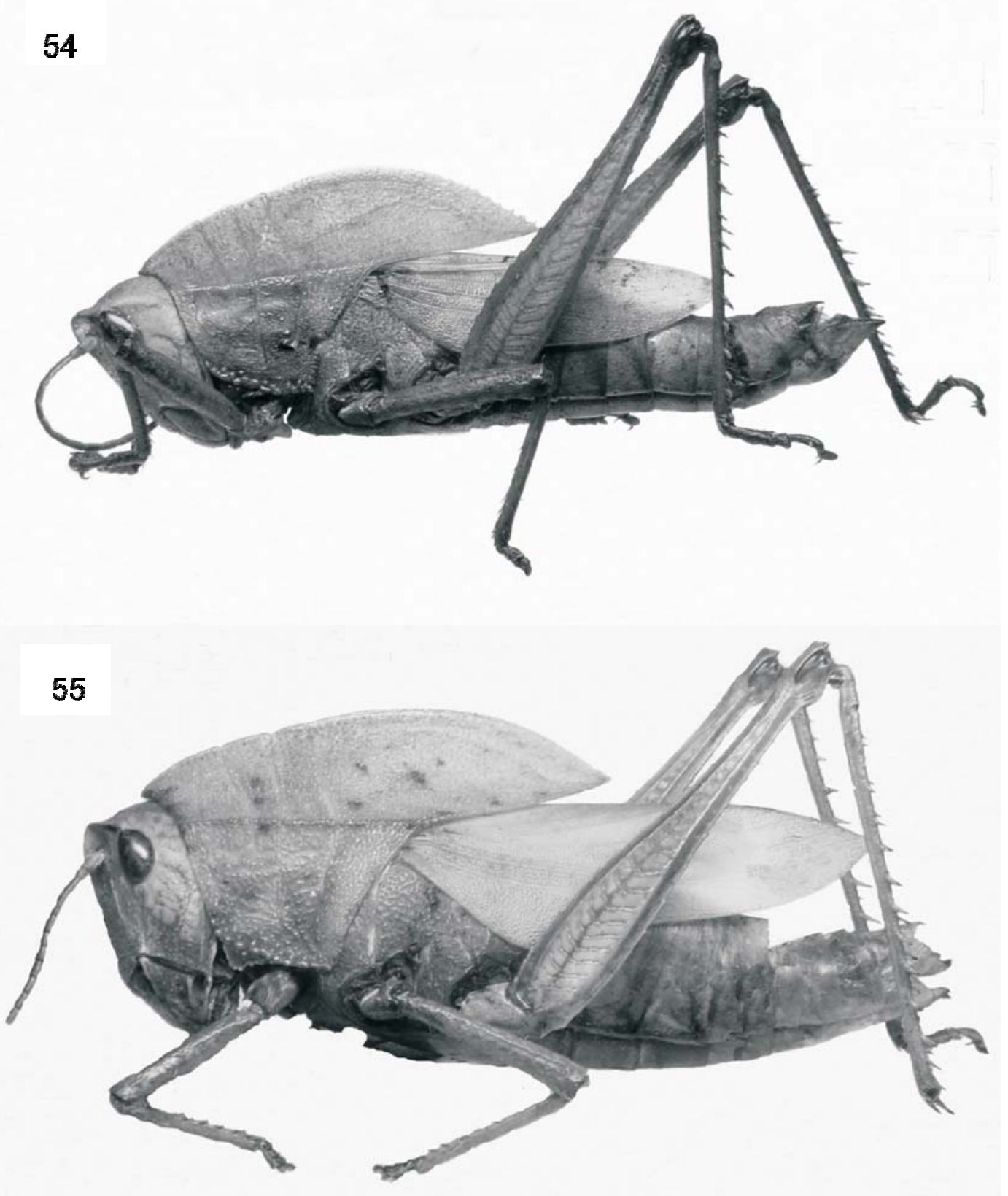

Figs. 54-55. Securigera cristata (Bruner, 1906) comb. nov.: 54, ơ, espécime de Perdidos, Mato Grosso, Brasil, comprimento, 39 mm; 55,, , Bonito, Mato Grosso, Brasil, comprimento, $47 \mathrm{~mm}$.

\section{DISCUSSÃO}

No que tange ao gênero Prionolopha, os estudos da morfologia externa e dos padrões de coloração revelaram uma variação destes aspectos em $P$. serrata, principalmente quanto à altura e uniformidade da curvatura da crista média do pronoto. Com relação aos diferentes padrões de coloração, constatamos que isso efetivamente ocorre. A tonalidade verde dos machos varia de um tom pálido até um oliva-escuro. Já nas fêmeas, a diferença mais instigante é a cor das faixas dorsais que podem ser amarelas, vermelhas ou ausentes. Neste contexto é importante salientar que tais variações ocorrem em diferentes exemplares independentemente da procedência, e que o mesmo não se verifica na morfologia da espermateca e do complexo fálico. Pelo contrário, a espermateca é uniforme morfologicamente, independentemente do fato dos exemplares possuírem ou não faixas dorsais amarelas ou vermelhas. O complexo fálico também é uniforme nos exemplares de diferentes localidades e padrões cromáticos.

O exame do material demonstrou que, apesar da variação morfocromática externa do gênero, conforme observação dos autores citados, a uniformidade morfológica do complexo fálico e da espermateca apenas confirma a coespecificidade das diferentes formas. Assim sendo, as características de coloração 


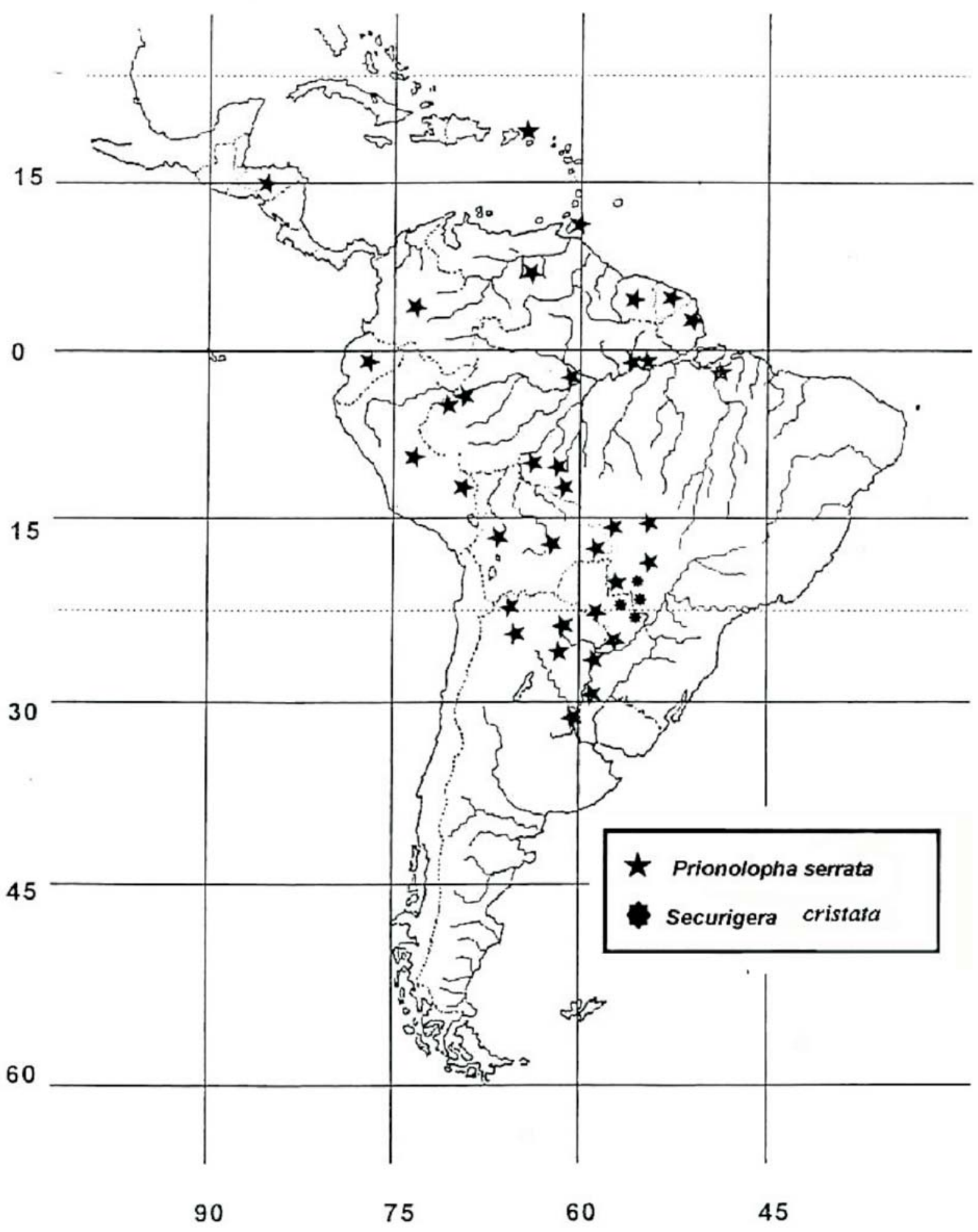

Fig. 56. Distribuição geográfica de Prionolopha serrata e Securigera cristata. 
e morfologia externa utilizadas na definição de $P$. daguerrei e $P$. evoneoi, conforme descrições originais, não encontram respaldo na morfologia da espermateca nem do complexo fálico. Baseado nisso, consideramos essas duas espécies descritas por Liebermann e Piza, respectivamente, sinônimas de $P$. serrata.

Quanto a Securigera, o exame da morfologia externa agregada aos caracteres do complexo fálico e espermateca contribuíram para confirmar a validade do gênero, diferenciando-o tanto de Prionolopha quanto de Alcamenes. A semelhança morfológica entre A. cristatus e $S$. acutangula chamou a atenção, sendo confirmada pelo exame da espermateca e complexo fálico. Por esta razão transferimos A. cristatus para Securigera, sendo $S$. cristata (Bruner, 1906) o epíteto da nova combinação.

Agradecimentos. Ao Prof. Dr. Miguel A. Monné (MNRJ), pela orientação e revisão do manuscrito. Ao Prof Carlos Salvador Carbonell (Universidade de la Republica, Montevideo, Uruguai), pelo empréstimo de fotografias dos tipos.

\section{REFERÊNCIAS BIBLIOGRÁFICAS}

Amedegnato, C. 1974. Les genres d'acridiens néotropicaux, leur classification par familles, sous-familles et tribus. Acrida 3:193-204.

Blanchard, E. 1840. Deuxiéme Ordre, Orthopteres. In: Histoire Naturelle des Insectes. Tome 3, Paris, 673p., 72 pl.

Bolívar, I. 1909. Acrididos nuevos americanos. Revista Chilena de História Natural 13(6):337-354.

Bruner, L. 1900. The second report of the Merchant's Locust Investigation Commission of Buenos Aires. Lincoln, 80 p.

1906a. Report on the Orthoptera of Trinidad, West Indies. Journal of the New York Entomological Society 14:135-165.

_. 1906b. Synoptic list of Paraguayan Acrididae or locust, with descriptions of new forms. Proceedings of the United States National Museum 30(1461):613-694.

1907. Acrididae. In: Biologia Centrali-Americana, London, 2:209-248.

. 1910. Report on a interesting collection of locust from Peru. Horae Societatis Entomologicae Rossicae 39:464-488.

1911. I. South American Acridoidea. Annals of the Carnegie Museum 8(1):5-147.

1913a. Results of the Yale Peruvian expedition of 1911. Orthoptera (Acrididae, Short-horned locusts). Proceedings of the United States National Museum 44(1949):177-187.

. 1913b. South American locusts (Acridoidea). II. Annals of the Carnegie Museum 8(3-4):423-506.

1919. I. Saltatorial Orthoptera from South America and the Isle of Pines. Annals of the Carnegie Museum 13(12):5-91.

Burmeister, H. 1838. Handbuch der Entomologie. Berlin, Zweiter Band. 1050p.

Campos, F. 1923. Estudios sobre la fauna entomológica del Ecuador. IX, Orthopteros. Revista del Colégio Nacional Vicente Rocafuerte 5(11-12):3-43.

Carbonell, C. S. 1986. Revision of the neotropical genus Tropidacris (Orthoptera, Acrididae, Romaleidae, Romaleinae). Proceedings of the Academy of Natural Sciences of Philadelphia 138(2):366-402.

1995. Revision of the tribe Scyllinini, nov. (Acrididae: Gomphocerinae), with descriptions of new genera and species. Transactions of the American Entomological Society 121(3): $87-152$.

COPR. (Centre for Overseas Pest Research). 1982. The locust and grasshopper agricultural manual. London, Centre for Overseas Pest Research. vii + 690p.

De GeEr, C. 1773. Onziéme memoire, Des croquets. In: Memoires pour servir a l'histoire des insects. Stockholm, Pierre Hesselberg. v 3, 697p.

D'Entreves, P. P. 1981. Cataloghi. IV - Collezioni ortotterologiche del Museo di Zooloia dell'Universita di Torino. Torino, Museo Regionale di Scienze Naturali. 127p.

Descamps, C. 1976. Le peuplement acridien d'un périmétre d'Amazonie colombienne. Annales de la Société Entomologique de France, (N.S.), 12(2):291-318.

1979. Missions entomologiques en Guyane et au Brésil. Troisiéme note: Orthoptera Acridomorpha. Annales de la Société Entomologique de France, (N.S.) 15(2):311-317.

Descamps, M. \& Amedegnato, C. 1970. Acridomorpha (Orthoptera) récoltés en Guyane Française par la mission du Muséum National d'Histoire Naturelle. Annales de la Société Entomologique de France, (N.S.) 6(4):861-897.

Dinther, J. M., VAN. 1960. Insect pests of cultivated plants in Surinam. Bulletin of the Agricultural Experiment Station 76:1-159.

Dirsh, V. M. 1956. The phallic complex in Acridoidea (Orthoptera) in relation to taxonomy. Transactions of the Royal Entomological Society of London 108(7):223-356.

Erichson, W. F. 1848. Insekten. In: SchomburgK, R. Versuch einer Fauna und Flora von British - Guyana. Reisen in British Guyana in den Jahren 1840-1841. Leipzig, Korte. v.3 1260p.

Fabricius, J. C. 1775. Systema Entomologiae, sistens insectorum classes, ordines, genera, species, adiectis synonymis, locis, descriptionibus, observationibus. Flensburgi \& Lipsiae, Korte. 832p.

1781. Species Insectorum exhibentes eorum differentias specificas, synonyma, auctorum, loca natalia, metamorphosin, adiectis observationibus, descriptionibus. Hamburgi \& Kilonii, Bohn, 1: viii $+552 \mathrm{p}$.

Gangwere, S. K. \& Ronderos, R. A. 1975. A synopsis of food selection in Argentine Acridoidea. Acrida 4:173-194.

Giglio-Tos, E. 1894. Viaggio dell dott. Alfredo Borelli nella Republica Argentina e nel Paraguay. VI, Ortotteri. Bolletino dei Musei di Zoologia ed Anatomia Comparata della R. Universita di Torino 9(184):1-46.

1895. Ortotteri del Paraguay, racolti dal Dr. J. Bohls. Zoologischen Jahrbucher 8:804-818.

1897. Viaggio del Dott. A. Borelli nel Chaco Boliviano e nella Republica Argentina. X, Ortotteri. Bollettino dei Musei di Zoologia ed Anatomia Comparata della R. Universitá di Torino 12(302):1-47.

1898. Viaggio del Dr. Enrico Festa nella Republica dell Ecuador e regioni vicine. VI, Ortotteri. Bollettino dei Musei di Zoologia ed Anatomia Comparata della R. Universitá di Torino 13(311):1-108.

1900. Viaggio del Dr. A. Borelli nel Matto Grosso e nel Paraguay. IV, Ortotteri. Bollettino dei Musei di Zoologia ed Anatomia Comparata della $R$. Universitá di Torino 15(377): $1-8$.

Hayward, J. K. 1960. Insectos tucumanos perjudiciales. Revista Industrial y Agrícola de Tucumán 42(1):3-144.

Hebard, M. 1931. Die Ausbeute der deutschen Chaco-Expedition 1925/26. Orthoptera. Konowia. Zeitschrift für systematische Insektenkunde 10(4):257-285.

Hepper, H. C. 1945. Notas ecológicas, sistemáticas y zoogeográficas de acridios de la Argentina. Revista de la Sociedad Entomológica Argentina 12(4):280-298.

Kirby, W. F. 1910. A synonymic catalogue of Orthoptera. Vol. 3. Orthoptera Saltatoria. Part. 2. (Locustidae vel Acrididae). London, British Museum. 674p.

Liebermann, J. 1928. Preliminares para el estudio de los acridoideos argentinos. Anales de la Sociedad Científica Argentina 104:137-158.

1935. Catálogo sistemático y razonado de acridoideos argentinos. Géneros: Prionolopha, Diedronotus, Elaeochlora y Chromacris (Orthop., Acrididae). Revista de la Sociedad Entomológica Argentina 7:25-50.

1939. Catálogo sistemático y biogeográfico de acridoideos argentinos. Revista de la Sociedad Entomológica 
Argentina 10:125-230.

. 1946a. Sobre una colección de acridios (Orth. Acrididae) del Instituto Miguel Lillo. Acta Zoologica Lilloana 3(2):235238 .

. 1946b. Sobre una colección de acridios paraguayos de la Misíon Científica brasileña 1940 - 1944 (Orth. Acrid.). Revista de Entomologia 17(3):452-456.

. 1951. Los acridios de Corrientes. IDIA (42-43):39-48.

- 1955. Primeira relação sistemática dos acridoideos do Brasil. Memórias do Instituto Oswaldo Cruz 53(2-3-4):329344.

__ 1957. Materiales típicos de acridios en las colecciones entomológicas de la Argentina. IDIA 116:17-20.

. 1958. Los acridios de Formosa (Orth. Caelif. Acridoidea). Publicación Técnica del Instituto de Patologia Vegetal 5:1-24.

. 1963. Sinopsis bibliográfica de los acridoideos del Perú. Revista Peruana de Entomologia Agrícola 6(1):61-66.

Liebermann, J. \& Piran, A. A. 1941. Primera lista de acridios uruguayos. Dirección General y de Contralor de la Lucha Contra la Langosta $12 \mathrm{p}$.

Liebermann, J. \& Ruffinelli, A. 1946. Catálogo de acridoideos uruguayos. Revista de la Asociación de Ingenieros Agrónomos 74:9-21.

Linnaeus, C. 1758. Systema Naturae per regna tria Naturae, secundum Classes, Ordines, Genera, Species, cum characteribus, differentiis, synonymis, locis. Editio decima reformata, Holmiae, 1:1-823.

1764. Insecta exotica. Pars 1. In: Museun Ludovicae Ulricae Reginae. Holmiae, Salvius. viii +720 p.

Marshall, J. A. 1983. The orthopteroid insects described by Linnaeus, with notes on the Linnean collection. Zoological Journal of the Linnean Society 78:375-396.

MAson, J. B. 1969. The tympanal organ of Acridomorpha (Orthoptera). EOS 44:267-355

Mesa, A.; Ferreira, A. \& Carbonell, C. S. 1983. Cariologia de los acridoideos neotropicales: estado actual de su conocimiento y nuevas contribuciones. Annales de la Société Entomologique de France, (N.S.) 18(4):507-526.

Monné, M. A. 1990. Lista sistemática dos Acridoidea (Orthoptera) da região da Chapada dos Guimarães, pp. 105110. In: Levantamento faunístico da área sob influência da BR - 364 (Cuiabá - Porto Velho). Brasília, Conselho Nacional de Ciência e Tecnologia. Programa Polonoroeste. 235p.

Olivier, A. G. 1791. Criquet, pp. 204-236. In: Encyclopedie Methodique, Histoire Naturelle. Insectes. Paris, Panckoucke. Tome 6, 704p.

Pictet, A. \& Saussure, H. De. 1887. Catalogue d'Acridiens. I. Bulletin de la Société Entomologique Suisse 7(9):331376.

PizA, S. DE T. 1981. Uma nova Prionolopha de Brasil (Orth. Acrididae, Romaleinae). Revista de Agricultura 56(12):81-82.

Rehn, J. A. G. 1907. Non-saltatorial and acridoid Orthoptera from Sapucay, Paraguay. Proceedings of the Academy of Natural Sciences of Philadelphia 59:151-192. 1909. On Brazilian grasshoppers of the subfamilies Pyrgomorphinae and Locustinae (Acridinae of authors). Proceedings of the United States National Museum 36(1661): 109-163.

1913. A contribution to the knowledge of the Orthoptera of Argentina. Proceedings of the Academy of Natural Sciences of Philadelphia 63:273-379.

1916. The Stanford Expedition to Brazil, 1911. Dermaptera and Orthoptera I. Transaction of the American
Entomological Society 42(753):215-308.

Rehn, J. A. G. \& Grant, H. J. 1959a. An analysis of the tribes of the Romaleinae with special reference to their internal genitalia (Orthoptera; Acrididae). Transactions of the American Entomological Society 85(1255.115):233-271.

1959b. A review of the Romaleinae (Orthoptera, Acrididae) found in America north of Mexico. Proceedings of the Academy of Natural Sciences of Philadelphia 111:109. 271 .

RoBERTS, H. R. 1941. A comparative study of the subfamilies of the Acrididae (Orthoptera) primarily on the basis of their phallic structures. Proceedings of the Academy of Natural Sciences of Philadelphia 93:201-246.

Scudder, S. H. 1868. Catalogue of the Orthoptera of North America described previous to 1867. Smithsonian Miscellaneous Collection. 189:1-89.

1901. Index to North American Orthoptera. Occasional Papers of the Boston Society of Natural History 6:1436.

Serville, J. G. A. 1831. Revue methodique des insectes de l'Ordre des Orthoptères. Annales des Sciences Naturelles 22:262292.

1839. Histoire naturelle des insectes Orthoptères. Collection des suites a Buffon, Paris. xvii $+776 \mathrm{p}$, Atlas, 4p., $+14 \mathrm{pl}$.

Silva, A. G. D’A.; Gonçalves, C. R.; Galvão, D. M.; Gonçalves, A. J. L.; Gomes J.; Silva, M. N. \& Simoni, L. DE. 1968. Quarto catálogo dos insetos que vivem nas plantas do Brasil, seus parasitos e predadores. Insetos, hospedeiros e inimigos naturais. Rio de Janeiro, Min. Agricultura. v.1, n. $2,622 \mathrm{p}$

SLIFER, E. 1939. The internal genitalia of female Acridinae, Oedipodinae and Pauliniinae (Orthoptera, Acrididae). Journal of Morphology 65(3):437-469.

Snodgrass, R. E. 1935. Principles of insect morphology. New York, McGraw-Hill. 667p.

STÅL, C. 1873. Recensio orthopterorum. Revue critique des Orthoptères décris par Linné, De Geer et Thunberg. Stockholm, Norstedt \& Söner. 105p.

1878. Systema acridiodeorum. Essai d'une systematisation des acridoidées. Bihang till Kongliga Svenska Vetenskaps-akademiens Handlingar 5(4):1-100.

Stoll, C. 1813. Naturlijke en naar leven nauwerkeurige gekleurde afbeeldingen en beschrijvingen der spoken, wandelende bladen, zabelspringhanen, krekels, trekspringhanen en kakkerlaken, in alle vier deelen del wereld Europa, Asia, Africka en Amerika. Amsterdam, J. C. Sepp et fils. v.1, 79p., 25 pl.; v.2, $28+42$ p., $13+23 \mathrm{pl}$.

Thunberg, C. P. 1815. Hemipterorum maxillosorum genera illustrata. Plurimsque novis speciebus dilata ac descripta. Mémoires de l'Académie Impériale des Sciences de St. Pétersbourg 5:211-301.

Uvarov, B. P. \& Dirsh, V. M. 1961. The diagnostic characters, scope and geographical distribution of the subfamily Romaleinae (Orthoptera: Acrididae). Proceedings of the Royal Entomological Society of London, (Series B) 30(1112): $153-160$.

WALKer, F. 1870. Catalogue of the especimens of Dermaptera Saltatoria in the collection of the British Museum (Natural History). London, British Museun Natural History. v.3, p.425-604.

Wattenwyl, K. B. von, 1893. Révision du système des Orthoptères et description des espèces rapportés par M. Leonardo Fea de Birmanie. Annali del Museo Civico di Storia Naturale di Genova, ser. 2 13:5-230. 